NASA/TM-2002-211559

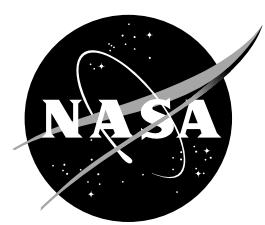

\title{
Low-Speed Fan Noise Reduction With Trailing Edge Blowing
}

Daniel L. Sutliff

SEST, Inc., Middleburg Heights, Ohio

Daniel L. Tweedt

AP Solutions, Inc., Cleveland, Ohio

E. Brian Fite and Edmane Envia

Glenn Research Center, Cleveland, Ohio 
Since its founding, NASA has been dedicated to the advancement of aeronautics and space science. The NASA Scientific and Technical Information (STI) Program Office plays a key part in helping NASA maintain this important role.

The NASA STI Program Office is operated by Langley Research Center, the Lead Center for NASA's scientific and technical information. The NASA STI Program Office provides access to the NASA STI Database, the largest collection of aeronautical and space science STI in the world. The Program Office is also NASA's institutional mechanism for disseminating the results of its research and development activities. These results are published by NASA in the NASA STI Report Series, which includes the following report types:

- $\quad$ TECHNICAL PUBLICATION. Reports of completed research or a major significant phase of research that present the results of NASA programs and include extensive data or theoretical analysis. Includes compilations of significant scientific and technical data and information deemed to be of continuing reference value. NASA's counterpart of peerreviewed formal professional papers but has less stringent limitations on manuscript length and extent of graphic presentations.

- TECHNICAL MEMORANDUM. Scientific and technical findings that are preliminary or of specialized interest, e.g., quick release reports, working papers, and bibliographies that contain minimal annotation. Does not contain extensive analysis.

- CONTRACTOR REPORT. Scientific and technical findings by NASA-sponsored contractors and grantees.
- CONFERENCE PUBLICATION. Collected papers from scientific and technical conferences, symposia, seminars, or other meetings sponsored or cosponsored by NASA.

- SPECIAL PUBLICATION. Scientific, technical, or historical information from NASA programs, projects, and missions, often concerned with subjects having substantial public interest.

- TECHNICAL TRANSLATION. Englishlanguage translations of foreign scientific and technical material pertinent to NASA's mission.

Specialized services that complement the STI Program Office's diverse offerings include creating custom thesauri, building customized data bases, organizing and publishing research results ... even providing videos.

For more information about the NASA STI Program Office, see the following:

- Access the NASA STI Program Home Page at http://www.sti.nasa.gov

- E-mail your question via the Internet to help@sti.nasa.gov

- Fax your question to the NASA Access Help Desk at 301-621-0134

- Telephone the NASA Access Help Desk at 301-621-0390

- Write to:

NASA Access Help Desk

NASA Center for AeroSpace Information 7121 Standard Drive

Hanover, MD 21076 
NASA/TM-2002-211559

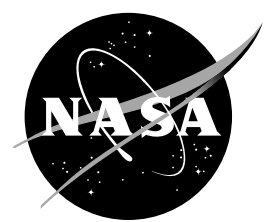

\section{Low-Speed Fan Noise Reduction With Trailing Edge Blowing}

Daniel L. Sutliff

SEST, Inc., Middleburg Heights, Ohio

Daniel L. Tweedt

AP Solutions, Inc., Cleveland, Ohio

E. Brian Fite and Edmane Envia

Glenn Research Center, Cleveland, Ohio

Prepared for the

Eighth Aeroacoustics Conference

cosponsored by the American Institute of Aeronautics and Astronautics and the Confederation of European Aerospace Societies

Breckenridge, Colorado, June 17-19, 2002

National Aeronautics and

Space Administration

Glenn Research Center

May 2002 


\section{Acknowledgments}

The CFD design was done as a part of a contract NAS3-00158, AP Solutions, Inc. Testing, analysis, and reporting were under contract NAS3-00170, SEST, Inc. The contributions of Earl Anderson and Sergy Samorezov, ZIN Technologies, Inc.; Richard Martin, Cleveland State University; Ken Weiland, Test Installation Division, Herb Lawrence, Manufacturing Engineering Division, Tony Shook, Mike Ernst, and Cameron Cunningham, Engineering Design and Analysis Division, and Dr. George Baaklini and Larry Heidelberg, Structures and Acoustics Division, NASA Glenn were vital.

Available from

NASA Center for Aerospace Information 7121 Standard Drive

Hanover, MD 21076
National Technical Information Service 5285 Port Royal Road Springfield, VA 22100

Available electronically at http://gltrs.grc.nasa.gov/GLTRS 


\title{
LOW-SPEED FAN NOISE REDUCTION WITH TRAILING EDGE BLOWING
}

\author{
Daniel L. Sutliff* \\ SEST, Inc. \\ Middleburg Heights, Ohio 44130 \\ Daniel L. Tweedt ${ }^{\dagger}$ \\ AP Solutions, Inc. \\ Cleveland, Ohio 44135 \\ E. Brian Fite ${ }^{\dagger}$ and Edmane Envia \\ National Aeronautics and Space Administration \\ Glenn Research Center \\ Cleveland, Ohio 44135
}

\begin{abstract}
An experimental proof-of-concept test was conducted to demonstrate reduction of rotor-stator interaction noise through rotor-trailing edge blowing. The velocity deficit from the viscous wake of the rotor blades was reduced by injecting air into the wake from a trailing edge slot. Composite hollow rotor blades with internal flow passages were designed based on analytical codes modeling the internal flow. The hollow blade with interior guide vanes creates flow channels through which externally supplied air flows from the root of the blade to the trailing edge. The impact of the rotor wakestator interaction on the acoustics was also predicted analytically.

The Active Noise Control Fan, located at the NASA Glenn Research Center, was used as the proof-ofconcept test bed. In-duct mode and farfield directivity acoustic data were acquired at blowing rates (defined as mass supplied to trailing edge blowing system divided by fan mass flow) ranging from 0.5 to $2.0 \%$. The first three blade passing frequency harmonics at fan rotational speeds of 1700 to $1900 \mathrm{rpm}$ were analyzed. The acoustic tone power levels (PWL) in the inlet and exhaust were reduced 11.5 and $-0.1,7.2$ and $11.4,11.8$ and 19.4 PWL dB, respectively. The farfield tone power levels at the first three harmonics were reduced 5.4, 10.6, and 12.4 dB PWL. At selected conditions, two-component hotwire and stator vane unsteady surface pressures were acquired. These measurements illustrate the physics behind the noise reduction.
\end{abstract}

\footnotetext{
"Senior Aeroacoustics Researcher, Senior Member AIAA

Aerospace Engineer

Aerospace Engineer, Senior Member AIAA
}

\begin{tabular}{ll} 
& \multicolumn{1}{c}{ Acronyms and Symbols } \\
AAPL & Aero-Acoustic Propulsion Laboratory \\
ANCF & Active Noise Control Fan \\
BPF & blade passing frequency \\
C & chord length \\
HP & horse power \\
ins & inserts \\
L/D & length-to -diameter ratio \\
m & circumferential mode order \\
n & radial mode order \\
Mint & integrated fan mass flow \\
opt & optimum \\
PWL & power level \\
r & radial position \\
r/s & rotor stator interaction \\
R & duct radius \\
Rnom & nominal radius to farfield mics \\
rpmc & revolutions-per-minute, corrected \\
SPL & sound pressure level \\
TERB & Trailing Edge Rotor Blowing \\
U & upwash velocity \\
V & mean velocity \\
$\alpha$ & mean flow angle \\
$\beta$ & stator vane angle \\
$\sigma$ & hub-to-tip-ratio \\
&
\end{tabular}

Introduction

The velocity deficit due to the viscous wakes of the rotor blades is a prime component of rotor-stator interaction noise. ${ }^{1}$ The periodic wake disturbance interacts with the stator causing unsteady surface pressures on the stator vane that in turn couple to the 
duct acoustic modes. The strength of the deficit correlates to the acoustic levels. It has been demonstrated analytically that reducing the harmonic content of the wake will have a substantial effect on reducing the tone component of the fan noise.

One method to reduce the velocity deficit is to fill the wakes by injecting air into the wakes from a slot in the trailing edge. Prior experiments using rotor trailing edge blowing in a blow-down facility ${ }^{2}$ and inlet guide vane trailing edge blowing ${ }^{3}$ have shown that filling the wake through trailing edge blowing reduces the harmonic content of the wake that is responsible for interaction tones.

Composite hollow rotor blades were designed for this experiment with interior passages consisting of a plenum and guide vanes to create flow channels through which air is channeled from the root of the blade to the trailing edge. The air for this experiment is supplied by a separate external 3-lobed rotary positive displacement blower. Analytical codes were used to determine the optimum shape of the internal passages and predict the injected wake characteristics along the blade span. The analytical codes also modeled the mixing of the injected flow with the free stream. This 'mixed' wake profile was then used as input to an analytical noise prediction code to determine the optimum design-blowing rate.

The trailing edge slot created a thick or blunt trailing edge that with no blowing, was unsuitable for baseline noise measurements due to vortex shedding. Therefore, a set of inserts that created a sharp trailing edge was installed to more closely model a realistic rotor blade. Although this extended the chord approximately $0.5 \mathrm{in}$. (nominal chord, 5 in.) this effect was ignored and the rotor blades with inserts were defined as the baseline rotor for comparison.

Blowing rates (defined as mass flow injected at trailing edge divided by fan mass flow) of 0.5 to $2.0 \%$ at fan rotational speeds of 1500 to $1900 \mathrm{rpm}$ were tested. Induct acoustic mode, two-component hotwire velocity, stator vane surface unsteady pressure, farfield directivity acoustic data, and fan flow performance data were acquired. The optimum blowing rate for reducing the tone noise was found to be between 1.6 and $1.8 \%$. In addition, a low blowing rate of about 0.5 to $0.6 \%$ occurs due to the centrifugal force from the rotation. For this paper, this is defined as self-blowing.

\section{$\underline{\text { Experimental Apparatus }}$}

\section{$\underline{\text { ANCF Test Bed }}$}

A proof-of-concept test was performed on the NASA Glenn 48 in. Active Noise Control $\mathrm{Fan}^{4}$ (ANCF). It is located in the Aero-Acoustic Propulsion Laboratory (AAPL) shown in figure 1a. The ANCF is a ducted fan used to test noise reduction concepts (figure $1 \mathrm{~b}$ ). The four foot diameter fan produces a tip speed of 425 ft/sec resulting in a Blade Passing Frequency (BPF) of approximately $500 \mathrm{~Hz}$. A 16-bladed rotor in combination with a variable stator vane count and spacing produces the desired rotor-stator interaction modal content. For the Trailing Edge Rotor Blowing (TERB) test, 14 stator vanes at one-chord spacing were used. This combination results in a single rotor-stator interaction mode each at $1 \mathrm{BPF}$ and $2 \mathrm{BPF}$, two modes at 3BPF.

\section{Trailing Edge Blowing Rotor}

The ANCF facility was chosen for this experiment because the relatively low speed allows for a relatively simple design. Sixteen composite hollow rotor blades were installed in the ANCF for this experiment. A photograph of the installed blades is shown in figure $1 \mathrm{c}$.

The final blade construction is rather complex. Figure 2 a shows a model of the assembled blade with the pressure side skin removed to illustrate the flow passages. Figure $2 \mathrm{~b}$ shows an exploded diagram of the blade components. Each component is fabricated separately. The base is axisymmetric to allow for fan stagger changes and is fabricated from aluminum. The internal flow channels are created by an internal sintered part and the airfoil skins. The forward and aft flow channel boundaries are contained in a single component fabricated using laser-sintering techniques. Blade skins are made of graphite/epoxy laminates. Final assembly is completed through use of a cast mold that locates and holds the components while adhesive is cured to consolidate the components. The internal geometry is critical in delivering the air to the trailing edge with minimal losses. Care was taken to assure best possible surface finishes on all wetted areas. In addition, the base of each fan blade was matched to its mating supply channel in the hub. The hub contained an impeller device that accepted flow from the central drive shaft, turned the flow radial, and delivered it to the fan blade with the proper rotational velocity. A lug on the base of each blade was matched to the top of each impeller channel to fix the blade-setting angle. Introducing the supply air through the facility drive shaft allowed the injection air to be introduced into the ANCF rig without affecting the existing flow path and measurement envelopes leading to a cleaner research assessment of the technology capability.

\section{Installation on ANCF}

The injection of mass flow through the rotor required a delivery system. The rotor shaft was the obvious design choice. An 8 in. diameter supply pipe and hose led from a 3-lobed rotary positive displacement blower to the aft 
base support of the rig. The single pipe was split into four flexible $4 \mathrm{in}$. diameter hoses which were further reduced to $3 \mathrm{in}$. before each enters the aft centerbody of the ANCF and finally the aft bearing manifold shown in figure $3 \mathrm{a}$. Four ports in the aft bearing manifold accept injection air from the 3 in. flexible hoses and supply it to a circumferential plenum that surrounds the drive shaft. From the plenum, air enters the shaft through four helical slots that include angled sides, $15^{\circ}$, to match the incoming flow angle at the design point speed and injection air Mach number through the slot. The passage in the shaft is $5 \mathrm{in}$. diameter, reducing to $3.6 \mathrm{in}$. at the entrance to the impeller at the right in figure $3 \mathrm{a}$. The impeller (a sintered part for low cost) turns the flow from axial to radial (and spinning at the rotor speed) and divides the flow among 16 rectangular passages of approximately $0.5 \mathrm{in}$. thick by $0.75 \mathrm{in}$. wide that supply air to the base of each rotor blade (figure $3 b$ ).

\section{Analytical Prediction Methodology}

\section{Flow}

The ANCF/TERB rotor was designed using a modified version of the NASA developed compressor design program $^{5}$ in conjunction with a three-dimensional viscous computational fluid dynamics (CFD) code for turbomachinery, RVC3D..$^{6-8}$ Through an iterative design process, several key aerodynamic parameters needed by the design code were obtained and adjusted based on the CFD simulation results. In particular, the span wise distributions of blade row total-pressure loss and exit flow deviation angle (turning) were determined from the CFD solutions. A two-dimensional viscous CFD code, DVC2D, ${ }^{9}$ was used to a limited extent, for example, to simulate the flow field in the axisymmetric inlet upstream of the rotor, providing inlet boundary condition data for the rotor computational domain.

Since it was desirable to use the existing stator with the TERB rotor, an RVC3D simulation was performed for the stator using flow conditions obtained from the rotor simulation. These results indicated that the existing stator would work well with the TERB rotor.

Simulations of the TERB ANCF rotor were performed using the RVC3D code augmented with a onedimensional flow model for the TERB flow characteristics. The one-dimensional model provided span wise distributions of total-pressure, totaltemperature, and flow direction for the TERB jet, based on flow conditions specified at the rotor center line where the TERB supply flow enters the rotor and was assumed to have known conditions. The model included the effects of rotation (centrifugal pumping, work) on the TERB air flowing through the hollow rotor disk and blades, as well as the total-pressure losses associated with those internal channel flows. Estimates of the totalpressure losses were obtained largely from DVC2D and RVC3D simulation results for portions of the internal flow passages and guide vane array. The resulting simulated (external) rotor flow field includes the TERB jet emitting from a narrow trailing-edge slot of varying width and extending over most of the blade span.

All rotor CFD simulations, with and without TERB, implemented the Baldwin-Lomax turbulence model ${ }^{10}$ for the effects of boundary layer and wake turbulence. In addition to providing valuable assessments of the ANCF rotor performance, the simulations also provided downstream flow field wake predictions suitable for acoustic analyses described in the next section.

It was known prior to CFD simulations that to fill the viscous wake momentum deficit the injection velocity must be higher than the relative flow velocity (figure 4a). That is since the injection slot height must necessarily be less the wake thickness. The design mass flow distribution was required to weighted to the tip necessitating an increasing slot thickness with span as shown in figure $4 \mathrm{~b}$.

Aeroacoustic Analysis of the Design of the Trailing Edge Blowing Fan

To estimate the noise benefits of the proposed design for rotor trailing edge blowing, the aeroacoustic performance of the ANCF with and without trailing edge blowing was analyzed using the $V 072^{11}$ code prior to the test. For a given rotor gust input (i.e., fan wakes), the V072 code computes the three-dimensional acoustic response of the stator vanes to an incident gust on a harmonic basis. The code utilizes simplified descriptions of the rotor and stator geometry and aerodynamics to provide estimates of the acoustic mode levels produced by the interaction of rotor wakes with the stator vanes. The accuracy of the predictions can be improved by utilizing measured or CFD-based threedimensional descriptions of the rotor wake. ${ }^{12}$ CFDbased wakes generated as part of the "blown" rotor design process were used to provide the necessary gust input to the V072 code for the results presented herein.

Mode levels produced by several different blowing rates were computed. The predictions were carried out for the first three harmonics of the blade passing frequency tone with 0.0 (i.e., no-blowing), 1.9, 2.0, and $2.1 \%$ blowing rates. Based on these results, it was thought that the $2.0 \%$ blowing along part of the span would offer the optimal combination of aero and acoustic benefits for rotor trailing edge blowing. In assessing these theoretical benefits, no consideration was given to the potential broadband noise impact of the rotor trailing edge blowing (e.g., vortex shedding from a blunt trailing edge). Neither was the self-noise 
that might be produced by the unconventional trailing edge design of the slotted trailing edge considered in the analysis.

\section{Data Acquisition Methodology}

A schematic of the ANCF with measurement locations is shown in figure 5 .

\section{Flow and Performance}

A radial rake with total pressure probes and a traversing static pressure probe, both located at the duct exit plane, were used to compute the mass flow as a function of corrected rpm (rpmc). The mass flow at a given rpmc was used to determine the percentage blowing rate. The bulk Mach number used for mode power levels at the inlet, rotor, and exhaust duct planes was calculated from the mass flow. The fan controller provided horsepower and torque. These data are presented on figure 6 .

\section{Hotwire}

Two component hotwire data (axial and tangential) were acquired one rotor chord ( 5 in.) behind the rotor at 15 to 25 radial positions. Hotwire data at $1800 \mathrm{rpm}$ for the baseline rotor, self-blowing, and optimum-blowing cases were acquired.

Hotwire time histories were acquired synchronous to the shaft rotation at 640 samples-per-revolution for 500 revolutions. The two-component time histories were converted to velocity and flow angle using a 2-dimensional fourth-order polynomial curve fit obtained from an off-line calibration in a free jet over the expected experiment velocity and flow angles. This calibration was at a single temperature. This temperature was fixed $\left(\sim 70{ }^{\circ} \mathrm{F}\right)$ due to the shop air delivery system.

The velocity and flow angle as a function of time were time-domain-averaged over a complete revolution, then further averaged over a single blade passage (40 points), and finally fully circumferentially averaged to obtain the mean flow values.

The physical noise generation mechanism is the unsteady upwash on the stator vane. The upwash is defined as the fluctuation in the normal velocity vector. Here it is defined as:

$$
\mathrm{U}_{\mathrm{r}}(\mathrm{i})=\mathrm{V}_{\mathrm{r}}(\mathrm{i}) * \cos \left[\alpha_{\mathrm{r}}(\mathrm{i})-\beta_{\mathrm{r}}\right]
$$

$$
\begin{aligned}
& \text { where } \\
& \begin{array}{l}
\mathrm{U}=\text { the upwash } \\
\mathrm{V}=\text { the flow velocity } \\
\alpha=\text { the flow angle } \\
\beta=\text { the stator vane angle } \\
\mathrm{r}=\text { denotes a fixed radial position }
\end{array}
\end{aligned}
$$

$\mathrm{i}=$ position in the wake passage

Typically, voltage values obtained from a hotwire must be corrected if the experimental temperature is different from the calibration. The experimental temperature is often not known exactly due to limitations in placement of a temperature measurement device. In addition, the temperature may vary in any of the dimensions hotwire data is acquired. Generally, this is not a major cause for concern since (1) the temperature variation during the 500 revolutions acquired is small; (2) the exact mean values are of less concern than relative or fluctuating values. Therefore, a single bulk experimental temperature is often used to correct all voltage measurements in a given run.

Using a single temperature across the entire revolution was unacceptable in this case because of the significant temperature rise in the injected air. The fan drew air from ambient conditions and had a small $\left(\sim 1\right.$ to $\left.2{ }^{\circ} \mathrm{F}\right)$ rise. However, the compressor that supplied the injected air had a (30 to $40{ }^{\circ} \mathrm{F}$ ) temperature rise. In addition, the large temperature difference between the calibration $\left(\sim 70{ }^{\circ} \mathrm{F}\right)$ and the experiment $\left(\sim 30\right.$ to $\left.40^{\circ} \mathrm{F}\right)$ is probably greater than can be accurately adjusted by the standard temperature correction.

Therefore the two overheat method $^{13}$ was used to determine the true velocity and temperature across a passage. The hotwire probe was calibrated and data acquired behind the rotor at two overheat ratios. Data were processed and a temperature profile due to the injection of the hotter air was assumed. The reduction procedure outlined earlier was modified by assuming the temperature profile across each blade wake at a given radial location due to injection was identical (i.e., no blade-to-blade variation in the injected profile.) The assumed temperature correction was applied to each overheat data set independently. The passageaveraged velocity was calculated based on applying the correction from the temperature profile across the passage (40 points). The velocity at a given point in the passage from each overheat data set was compared. The temperature at that given point in the circumferential passage was adjusted by iteration until the velocities from each overheat data set agreed to within $0.5 \mathrm{fps}$. Thus, passage averaged velocity and temperature profiles were obtained from the reduction process simultaneously.

Figure 7 shows the results with bulk temperature correction and iterated passage-averaged temperature correction for a typical radial location of self-blowing and optimum-blowing cases. The significant temperature rise in the wake changes the reduced velocity profile substantially when compared to the uncorrected, presumably inaccurate, profile obtained using a constant temperature across the passage profile. 
The self-blowing case brought air into the passages through a duct whose inlet was 10 feet below the duct centerline. From operational experience, there are known to be significant vertical temperature gradients inside the AAPL facility. The iteration process indicates that the temperature in the wake is indeed cooler, to a maximum of $\sim 5^{\circ} \mathrm{F}$ cooler near the wake centerline.

For the blowing case, it is expected that there is a temperature rise in the wake. The iterative method indicated that the peak rise is $\sim 4.5{ }^{\circ} \mathrm{F}$ near the centerline. In addition, the variation in the wake results in an iteratively converged velocity that has a significantly different characteristic than the velocity profile from either overheat ratio. The presumed actual velocity profile is overblown, a characteristic not indicated from the unadjusted profiles. In addition, both cases have nearly identical $\left(\sim 11.5^{\circ} \mathrm{F}\right)$ bulk temperature increases that are probably due to the error in temperature that arise from the different locations of the hotwire and the temperature measurement device; and a systematic error in the temperature correction due to the large difference between the calibration and the experiment.

These adjustments produce physically reasonable results, though unconfirmed by independent measurement. However, it is noted that the analytical profile solution (see Comparison to Analytical Results section) for the optimum-blowing case is predicted to be slightly overblown. The adjusted profile matches this profile better. The constant temperature correction derived in the inviscid portion of the velocity profile indicates the correction is valid. In addition, the adjustments are similar across a wide variety of conditions. Therefore, all hotwire data presented herein are presented with this iteratively adjusted velocity and temperature profile.

\section{$\underline{\text { Surface Pressures }}$}

Unsteady stator vane surface pressures were also acquired only at $1800 \mathrm{rpm}$ for the baseline rotor and optimum blowing rate. The suction and pressure side of a single stator vane were each instrumented with 30 microphones as detailed in figure 8. The microphones were flush mounted on the surfaces and distributed along three span locations $(r / R=0.49,0.74$, and 0.91 ) and a radial line at $20 \%$ chord.

The time histories were acquired synchronous to the shaft rotation at 256 samples-per-revolution for 500 revolutions. A frequency domain averaged FFT with an ensemble length of five revolutions was obtained from the time histories. The harmonics of the blade passing frequency up to the Nyquist frequency were obtained from the spectra, with the first three harmonics being of the most interest. The tonal component of the unsteady surface pressure has been demonstrated $^{14}$ to be directly related to the acoustic levels.

\section{$\underline{\text { Rotating Rake }}$}

The rotating rake instrumentation system provides a complete map of the duct modal signature at $1 \mathrm{BPF}$, $2 \mathrm{BPF}$, and $3 \mathrm{BPF}$ for either the inlet or exhaust duct. The circumferential modes arise from a Doppler induced frequency shift due to the unique and discrete rotation rate of each m-order. Radial modes (n) are computed from a least squares data fit of the radial pressure profile using hardwall Bessel functions as the basis functions. ${ }^{15}$ Rotating rake data were acquired for the entire fan speed range and blowing rates.

The modal data from the rotating rake will be presented in 3-D format. The base plane axes are $\mathrm{m}$ - and n-order, and the vertical value axis in the PWL in the $(m, n)$ mode. The mode power level is the sum of all cut-on rotor-stator interaction modes. Along the wall of the morder axis the sum of all the radials provides the power in that circumferential mode. The sum of all provides the PWL in the harmonic presented. The typical 3-D chart provides information as to the dominant modes present, usually those due to the rotor-stator interaction. Of secondary interest, are all other modes that may be due to inflow distortions (often called extraneous modes). Thus, a table for each 3-D chart will be presented to indicate the total power in the harmonic, the total power in just the rotor-stator interaction mode(s), and the power in the extraneous modes. The Tyler-Sofrin rotor-stator modes ${ }^{16}$ expected with 16 blades and 14 stators with their cut-on rotational speeds are presented on figure 10.

\section{Farfield}

Farfield acoustic data were also acquired over the entire range blowing rates and fan speeds. Twenty-eight microphones were distributed along an arc of approximately $40 \mathrm{ft}$. radius with $5^{\circ}$ increments. Figure 10 provides the farfield microphone locations. Data were synchronously sampled at 256 sample-perrevolution and were obtained by frequency domain five revolution ensembles. Tonal Sound Pressure Level (SPL) directivity was obtained at each blade passing harmonic. The SPL directivity was integrated over the directivity angle assuming constant SPL over the azimuthal angle to obtain the tone PWL.

\section{Experimental Results}

The rotating rake acoustic data was acquired first to determine the optimum-blowing rate. The optimum blowing rate was determined by the minimum of the summation of the first three tone PWLs. However, the data is presented from the noise generating mechanism to the ultimate metric, the farfield directivity. 
The design goal was to reduce the rotor-stator interaction mode at the fan blade passing frequencies. This was determined by comparing the levels for the first three harmonics for a given blowing rate and comparing to the baseline. Unless otherwise mentioned the results are for full span blowing.

\section{$\underline{\text { Rotor Wake }}$}

The circumferentially averaged mean values for velocity and flow angle as a function of radial span are presented in figure 11. These data are taken one rotor chord behind the rotor in the plane of the stator leading edge, although the stators are not present. Three basic conditions are presented: (a) rotors with trailing edge inserts installed, (b) the "self-blowing" case $(0.6 \%$ blowing rate), (c) optimum-blowing of $1.8 \%$. The baseline rotor velocity profile is reasonably uniform. The velocity profile with self-blowing also appears to be more uneven compared to that with inserts. This is probably due to the centripetal forces that create the self-blowing result in an un-even flow from the trailing edge, as well as a possibility of slight flow circulation between the passages. The self-blowing rate appears to reduce the velocity at the inner portion of the span. The velocity profile for the optimum-blowing rate is also similarly reduced at the inner span. Integrating the mean velocity profile along the radial direction for the case with inserts and comparing to the blowing cases indicates a slight decrease in overall mass flow $(-0.8 \%)$ with self blowing; and a increase in mass flow (1.4\%) with optimum blowing. The overall mass flow has been increased with optimum blowing, approximately the amount that has been injected.

The change in profile may be due to the blunt trailing edge causing vortex shedding or flow separation from the blade, which has been noted to reduce the mean flow. It is likely that the blowing prevents this undesirable flow from forming. This is especially true near the tip. However, by design, less mass flow is directed to the inner span. It is possible that in the inner span, vortex shedding/flow separation is occurring, resulting in the lower mean velocity. There is less point-to-point variation along the radial profile with the application optimum blowing due to the positive mass flow not allowing the circulation between passages. The angle profiles are similar for all three cases; with perhaps a slight decrease $\left(\sim 1\right.$ to $\left.2^{\circ}\right)$ in the turning angle as blowing is increased.

\footnotetext{
${ }^{8}$ Hotwire measurements were taken behind the rotor when the trailing edge was fully taped, creating a blunt trailing edge. These measurements showed a 5 to $10 \mathrm{fps}$ drop in the velocity profile across the span. The trailing edge taped rotor was judged unsuitable for an experimental baseline, but may have provided insights into the results with blowing.
}

The passage averaged circumferential velocity, flow angle, and upwash velocity as a function of radial position are presented in figure 12 as contour plots. Selected radial profiles from the circumferential passage are shown in figure 13. The self-blowing case actually increases the velocity deficit. This is probably due to the thickness of trailing edge (compared to the sharp trailing edge) creating a thick wake that the low blowing rate does not fill. The optimum-blowing rate actually over fills the wake, or over-blows, at radial stations from about $50 \%$ to the near the tip. The hub separation is greater with the thicker trailing edge, which is not remedied by increased blowing. The wake angle deviation is affected by blowing. The flow angle with self-blowing is somewhat less than with the inserts. The flow angle resulting when optimum blowing is applied is considerably less. The flow deviation reverses direction when the wake is overfilled. The result is that the upwash as calculated from Eq. (1) is modestly reduced over most of the radial span when self-blowing is applied, and considerably reduced with optimum blowing.

\section{$\underline{\text { Stator Vane Surface Pressures }}$}

The unsteady stator vane surface pressures for the first three harmonics at the $20 \%$ chord line are presented in figure 14 for the suction side and figure 15 for the pressure side. The unsteady pressure at the $20 \%$ chord line has been shown to be the major contributor to tone noise for this fan and indicative of the overall levels. ${ }^{13}$ The vane surface SPL for the case with the inserts and with self-blowing are approximately the same for all three harmonics. The surface SPLs with optimum blowing applied are significantly lower, especially near the tip. This is the case for both the suction and pressure sides of the stator vane. The optimum-blowing case shows an extreme minimum and a phase reversal near the $50 \%$ span. This location corresponds to the transition between under- and over-blowing indicated by the hotwire.

\section{Acoustic Duct Modes}

Figures 16, 17, and 18 show the modal decomposition for the inlet and exhaust for the first three fan harmonics. At BPF, in the inlet, with optimum-blowing a reduction in $\mathrm{m}=2$ of $11.5 \mathrm{~dB}$ occurs. In the exhaust a decrease of $5.0 \mathrm{~dB}$ is noted with self-blowing, but an increase of $0.1 \mathrm{~dB}$ results when optimum-blowing is applied.

The second harmonic rotor-stator mode $(\mathrm{m}=4$, with two radials) reductions are $7.2 \mathrm{~dB}$ (inlet) and $\mathrm{dB} 11.4$ (exhaust). It also becomes apparent that the non-rotor stator modes are reduced $1.5 \mathrm{~dB}$ (inlet) and $6.1 \mathrm{~dB}$ (exhaust). The overall harmonic PWL is reduced $6.4 \mathrm{~dB}$ and $10.4 \mathrm{~dB}$. 
The third harmonic rotor-stator interaction modes are reduced 11.8 and $19.4 \mathrm{~dB}$ with the application of optimum blowing. For the most part all modes are reduced to the measurement noise floor. The overall PWL reductions in the $3 \mathrm{rd}$ harmonic are $13.6 \mathrm{~dB}$ and $18.5 \mathrm{~dB}$ in the inlet and exhaust ducts, respectively.

The significance is that a reduction in the rotor-stator mode has a nearly 1-to-1 dB impact on the harmonic PWL. To the extent the 'extraneous' modes are due to the blade-to-blade rotor wake differences interacting with the stator rather than distortions in the inflow field reacting with the rotor this is an expected, but useful result.

The effect of varying the blowing rate from selfblowing $(0.6 \%)$ to $2.0 \%$ is presented in figure 19 . The lack of effectiveness at BPF maybe due to that harmonic being a result of the strong tip flow, which is not modified with the application of blowing. A second possibility is the BPF levels are from the interaction of the rotor potential field variation rather than the wake deficit interaction with the stator vane. At the second and third harmonics the clear minimum at $1.8 \%$ is noted. Also, note that this fan is dominated by the $(\mathrm{m}, 0)$ modes. Blowing reduces all radial modes reasonably uniformly.

The effect of blowing along only part of the rotor span was investigated by taping the trailing edge except for $20 \%$ span from the tip, with the results shown in figure 20 . It is seen that the minimum occurs at a lower blowing rate of about $1.1 \%$. (It is known that the design full-span flow rate is heavily tip weighted.) The reductions are approximately the same or a few $\mathrm{dB}$ less compared to full span blowing at $1.8 \%$. This is because the ANCF is dominated by the $(\mathrm{m}, 0)$ modes and filling the wake at $20 \%$ tip couples very well to the tipdominated $(\mathrm{m}, 0)$ modes. The reduction in the overall $\mathrm{m}$ order is primarily due to reduction in the $(\mathrm{m}, 0)$ mode. Unlike the full span blowing case, the higher modes are mostly unaffected by tip blowing. This indicates that carefully selected blowing at only spans that couple to dominant acoustics may result in lower blowing rates to accomplish similar reductions. However, the taped section of the rotor was effectively a blunt trailing edge that created enormous broadband noise, ${ }^{* *}$ which will be briefly described in the farfield results. If part-span

\footnotetext{
${ }^{* *}$ Note: farfield measurement were taken with two other rotor trailing edge conditions: (i) the rotor trailing edge completely taped, and (ii) the duct inflow to the blowing system completely blocked resulting in no net mass flow through the blade. These configurations resulted in modest changes in the tones but tremendous $(\sim 20 \mathrm{~dB})$ increases in the farfield broadband SPL at certain frequencies as would be expected $^{* *}$ from what is effectively a blunt trailing edge. It is only mentioned here to indicate that caution must be exercised when designing the rotor blade to anticipate blowing failure or partspan blowing conditions.
}

blowing is to be useful, resulting in lower blowing rates, very careful design to condition will be required.

The effect of blowing at other fan speeds resulted in similar mode level versus blowing rate profiles. Figure 21 compares interaction mode PWLs from the baseline case to the levels at the optimum blowing, as determine for each speed and harmonic. The maximum reduction generally occurs at $1.8 \%$. A few cases, mostly $\mathrm{BPF}$ in the exhaust, better reductions are obtained at lower blowing rates.

\section{Farfield Directivity}

The farfield directivities for the first three harmonics from 0.6 to $2.0 \%$ are presented in figure 21 . For each blowing rate, the tonal directivity is plotted along with the tonal directivity with rotor trailing edge inserts for comparison. The integrated tone PWL is noted on the plot. The farfield results confirm the in-duct mode measurements. For example, note the directivity for the first harmonic at optimum blowing (1.8\%): the inlet lobe is significantly lowered by $7.5 \mathrm{~dB}$ SPL at the peak of the lobe, but an increase of 1.2 dB SPL at the exhaust lobe peak. This matches the in-duct results very well. However, the farfield directivity indicates that $1.6 \%$ blowing produced greater reduction than $1.8 \%$ for all three harmonics. This is partially a result of uncertainty in the blowing mass flow measurement. The uncertainty in the blowing ratio is estimated to be about $\pm 0.05 \%$. An additional factor is that the presence of the exhaust rake may slightly back-pressure the fan effecting the measurements taken with the rotating rake. It may also be that finer blowing rate increments would identify a minimum that both sets of measurements agree upon.

\section{Comparative Tonal Summary}

The reductions in the tone harmonics calculated or measured from the different measurement methods are presented in figure 23. First, the average upwash across the radial span as measured by the hotwire is calculated from the FFT of the passage-averaged upwash. This is expected to correlate to the duct mode PWLs as outlined in references 2 and 11. The optimum-blowing harmonic upwash is referenced to that calculated behind the rotor with inserts. A reduction in the harmonic upwash of 8 to $10 \mathrm{~dB}$ is calculated. Next, the average SPL for all vane microphones for the first three harmonics is computed. This metric has been shown in reference 13 , for this fan only, to correlative very well to the in-duct mode PWLs. The measured in-duct and farfield PWLs are also presented. Overall, the trends and comparisons for each measurement method agree and compliment each other very well. 


\section{Comparison to Analytical Results}

The other goal of this project was to validate the flow and acoustic codes used as design tools. Comparisons of the experimental to the predicted data are presented in this section. The comparisons between the experimental data and CFD results are not at exactly matching conditions primarily because the hotwire data were acquired at 1 rotor chord ( 5 in.) behind the rotor, while the CFD results are $4.82 \mathrm{in}$. downstream of the rotor stacking axis, which corresponds to the CFD grid exit. That is, the CFD results are $2.7 \mathrm{in}$. upstream of the hotwire. Furthermore, for the baseline comparisons, the experimental results are from a sharp trailing edge, while that CFD results are from a rotor with a thicker trailing edge, though with out modeling the vortex shedding. Finally, it was decided to compare optimumblowing, to optimum-blowing as defined by the separate methodologies, i.e., $1.8 \%$ experiment versus $2.0 \%$ CFD.

\section{Performance}

The CFD results predicted the baseline fan would produce a mass flow of $131.7 \mathrm{lb}_{\mathrm{m}} / \mathrm{sec}$ at $2000 \mathrm{rpmc}$ at maximum absorbed horsepower. Experimentally (interpolating figure 6), the fan produced $131.5 \mathrm{lb}_{\mathrm{m}} / \mathrm{sec}$ at $1910 \mathrm{rpmc}$ at $100 \%$ horsepower. It is speculated from in-situ measurements that blade setting angle as installed was slightly higher than designed.

\section{Flow}

The comparison of mean wake profile behind the rotor is shown in figure 24 for the baseline. The turning angle agreement is excellent, with the code over predicting the angle by less than 1 to 2 degrees. The mean velocity comparison shows agreement within $5 \mathrm{fps}$ for the baseline rotor, about $10 \mathrm{fps}$ with blowing applied. More notable is the character of the profile. The code predicts a higher velocity at the hub. The experimental profile showed a uniform profile with no blowing, and noticeable unloading at the hub with blowing applied.

Figure 25 presents the wake profiles at the selected radial positions for the baseline rotor. In general, the code over-predicts the velocity deficits and the deviation angle. This is probably because the measurements correspond to a location further downstream, but also because the Baldwin-Lomax CFD may not have enough turbulent mixing ${ }^{17}$ in the wake. The phase of the CFD results was adjusted to account for convection by the mean swirl.

The comparisons in the wake profiles with blowing applied are shown in figure 26 . The code predicted the slight over-blowing near tip-ward and slight underblowing hub-ward. The code shows less deviation than was measured experimentally. This may be a result of uneven radial distribution in the experiment.
Acoustic

The predicted harmonic tone levels from V072 using the CFD results are compared to those measured by the rotating rake in figure 27 . The absolute levels for the baseline rotor and with blowing applied as well as the reductions obtained with blowing are presented. In general, the reductions due to blowing are estimated accurately, except for exhaust BPF. The analytical results predicted substantial reduction that was not measured experimentally in the exhaust.

\section{Conclusions}

The rotor blades of a low-speed fan were designed to reduce the rotor-stator interaction noise through the use of rotor trailing edge blowing. Composite hollow rotor blades were designed with internal passages to deliver the injected flow at the design pressure and flow rate to fill the wake momentum deficit. CFD and analytical codes were developed and used as tools to optimize the design.

Types of data acquired were: (i) two-component hotwire behind the rotor, (ii) unsteady surface pressures on a stator vane, (iii) acoustic duct modes, and (iv) farfield directivity. These data were analyzed for tonal character.

The rotating rake tonal analysis indicated that the viscous wake is essentially filled at a blowing rate of $1.8 \%$ of the fan mass flow rate. The optimum-blowing rate as defined by the minimum acoustic levels was between 1.6 and $1.8 \%$. Blowing had modest effects on the BPF tone in the exhaust. Blowing significantly reduced all rotor-stator interaction modes and other extraneous modes at the second and third harmonics. Acoustic tone power levels in the inlet and exhaust were reduced 11.5 and $-0.1,7.2$ and 11.4, 11.8 and 19.4 PWL dB, respectively, at the first three harmonics of the Blade Passing Frequency. The farfield directivity confirmed the reductions obtained. The reductions obtained in the farfield were 5.4 (1BPF), 10.6 (2BPF), and 12.4 (3BPF) dB tone PWL.

Reduction in the fan tone levels by filling the rotor viscous wake through trailing edge blowing has been demonstrated to achieve substantial tone reduction at 1.6 to $1.8 \%$ of the fan mass flow rate. Indirect methods indicate that broadband reduction of rotor-stator interaction noise may result.

The design codes used in this work were validated as reliable tools for predicting the behavior of trailing edge blowing for a low speed fan. Simulations of the TERB ANCF rotor using the RVC3D code, augmented with a one-dimensional flow model for the TERB flow characteristics, predicted the experimentally values very well. Using these results 
as input to the V072 acoustic code predicted the noise reductions obtained reasonably well.

Filling the viscous wake of the rotor through trailing edge blowing has been shown to be an effective method to reduce rotor-stator interaction tones.

\section{Future Work}

Preliminary analysis of the fan wakes and stator vane unsteady pressures indicate that there may also be a broadband noise reduction benefit from trailing edge blowing. This will be the subject of a follow-on paper.

\section{$\underline{\text { References }}$}

1. Hubbard, H. Harvey, editor, "Aeroacoustics of Flight Vehicles: Theory and Practice: Volume 1," NASA Reference Publication 1258, vol. 1, WRDC Technical Report 90-3052.

2. Brookfield, J.M., "Turbofan Rotor/Stator Interaction Noise Reduction Through Trailing Edge Blowing," Ph.D. Thesis, Massachusetts Institute of Technology, June 1998.

3. Rao, N.M., Feng, J., Burdisso, R.A., and Ng, W.F., "Experimental Demonstration of Active Flow Control to Reduce Unsteady Stator-Rotor Interaction," AIAA Journal, vol. 39, no. 3, March 2001.

4. Heidelberg, L.J., Hall, D.G., Bridges, J.E., and Nallasamy, M., "A Unique Ducted Fan Test Bed for Active Noise Control and Aeroacoustics Research," NASA TM-107213, AIAA 96-1740, May 1996.

5. Crouse, James E., and Gorrell, William T., "Computer Program for Aerodynamic and Blading Design of Multistage Axial-Flow Compressors," NASA TP-1946 (AVRADCOM TR 80-C-21), December 1981.
6. Chima, R.V., and Yokota, J.W., "Numerical Analysis of Three-Dimensional Viscous Internal Flows," AIAA Journal, vol. 28, no. 5, May 1990, pp. 798-806 (also NASA TM-100878).

7. Chima, R.V., "Viscous Three-Dimensional Calculations of Transonic Fan Performance," CFD Techniques for Propulsion Applications, AGARD Conference Proceedings No. CP-510, AGARD, Neuilly-Sur-Seine, France, February 1992, pp. 21-1 to 21-19 (also NASA TM-103800).

8. Tweedt, D.L., Chima, R.V., and Turkel, E., "Preconditioning for Numerical Simulation of Low Mach Number Three-Dimensional Viscous Turbomachinery Flows," AIAA-97-1828, July 1997 (also NASA TM-113120 and ICOMP-97-11).

9. Tweedt, D.L, and Chima, R.V., "Rapid Numerical Simulation of Viscous Axisymmetric Flow Fields," AIAA-96-0449, January 1996 (also NASA TM107103).

10. Baldwin, B.S., and Lomax, H., "Thin-Layer Approximation and Algebraic Model for Separated Turbulent Flows," AIAA 78-257, January 1978.

11. Meyer, H.D., and Envia, E., "Aeroacoustic Analysis of Turbofan Noise Generation," NASA CR-4715, March 1996.

12. Sutliff, D.L., Bridges, J., and Envia, Edmane, "Comparison of Predicted Low Speed Fan Rotor/Stator Modes to Measured," NASA TM107462, AIAA-97-1609, May 1997.

13. Brunn H.H., "Hot-Wire Anemometry: Principles and Signal Analysis," Oxford Science Publications, 1995.

14. Sutliff, D.L., Heidelberg, L.J., and Envia, E., "Coupling of Low Speed Fan Stator Vane Unsteady pressures to Duct Modes: Measured vs. Predicted," NASA/TM-1999-0209050, AIAA 99-1864, May 1999.

15. Sutliff, D.L., Nallasamy, M., Heidelberg, L.J., and Elliott, D.M., "Baseline Acoustic Levels of the NASA Active Noise Control Fan Rig," NASA TM-107214, AIAA 96-1745, May 1996.

16. Tyler, J.M., and Sofrin, T.G., "Axial Flow Compressor Noise Studies," SAE Transactions, vol. 70, 1962, pp. 309-332.

17. Chima, R.V., "A k- $\omega$ Turbulence Model for QuasiThree-Dimensional Turbomachinery Flows," AIAA Paper 96-0248 (also NASA TM-107051), January 1996. 


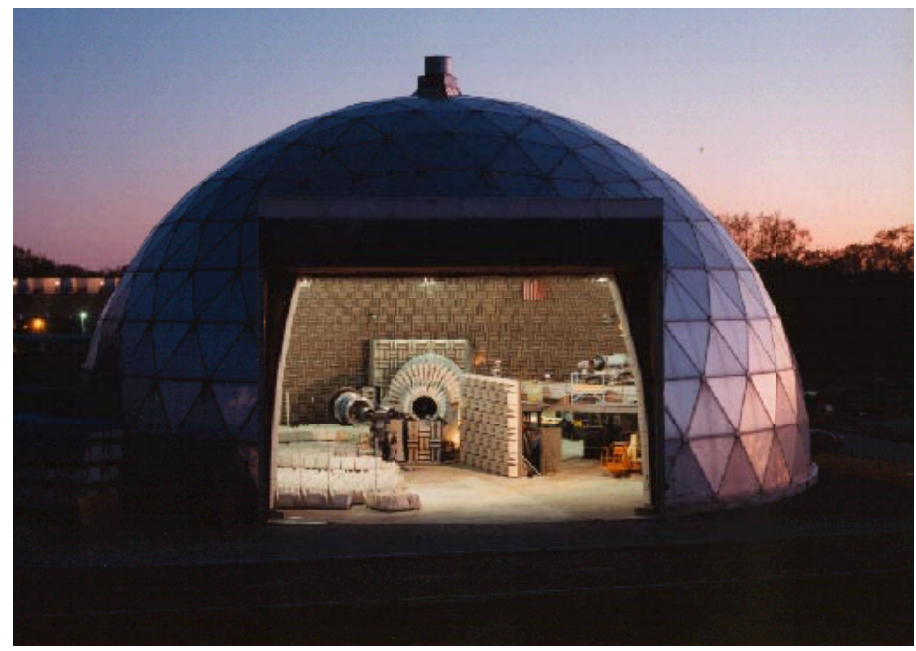

(a) Aero-Acoustic Propulsion Laboratory

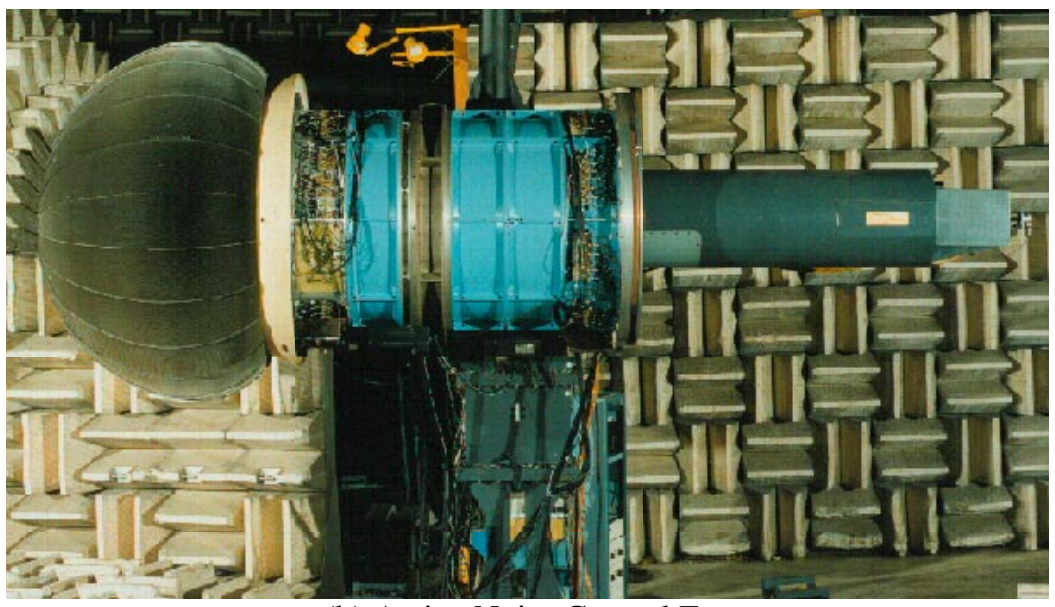

(b) Active Noise Control Fan

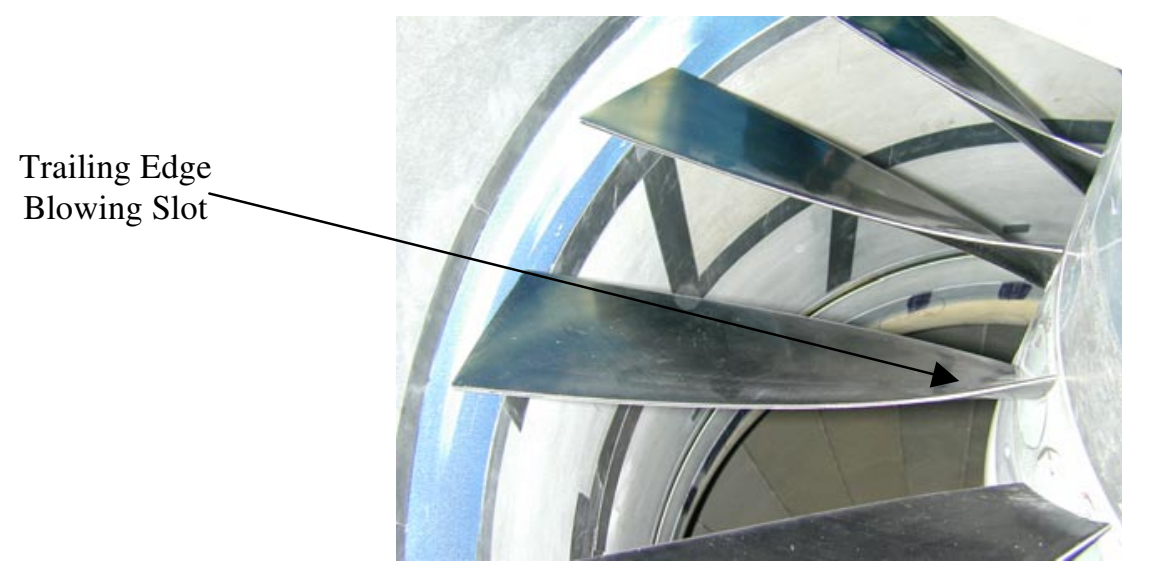

(c) Trailing Edge Rotor Blowing Installation viewed from downstream of fan

Figure 1. Experimental apparatus 


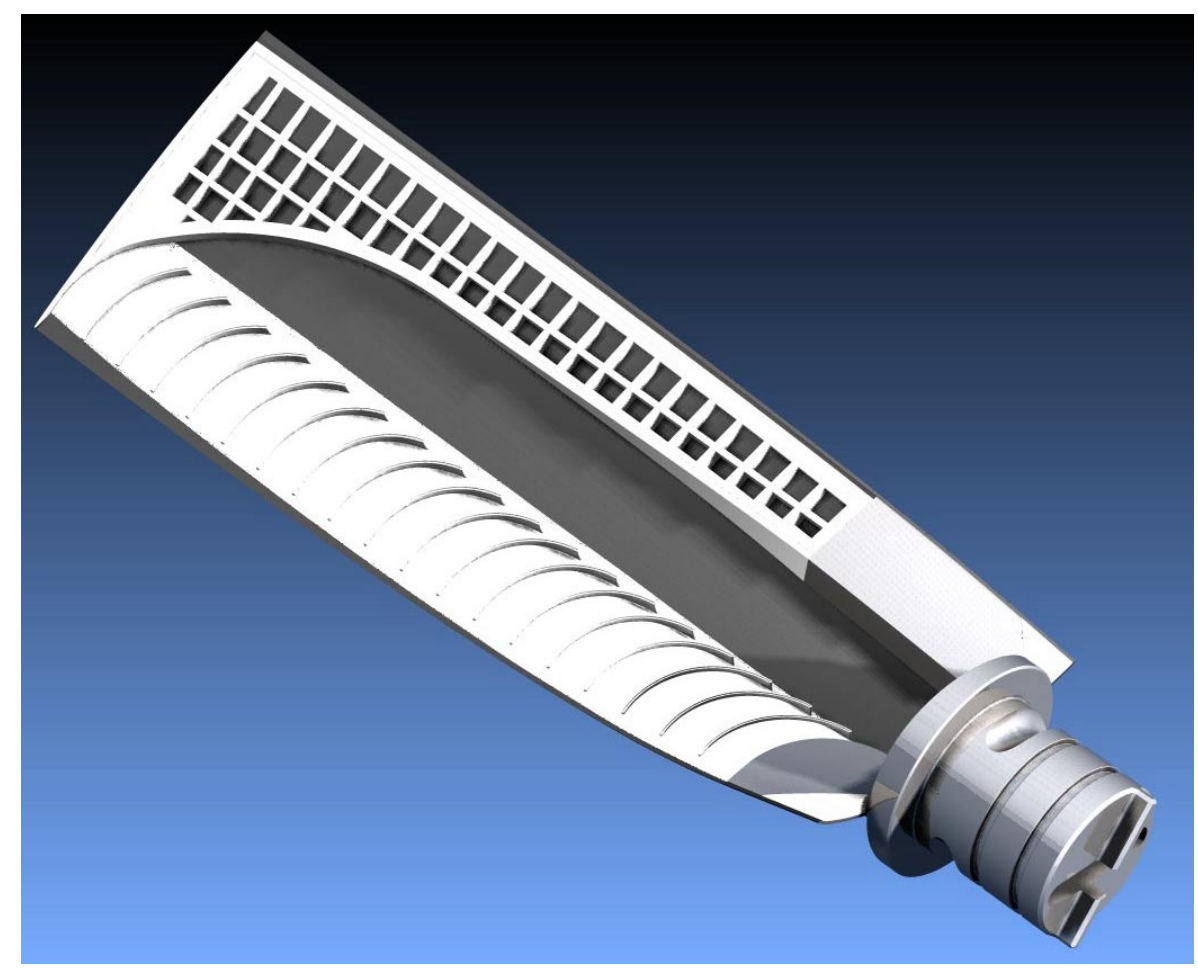

(a) ANCF Hollow Fan Blade with pressure side skin removed

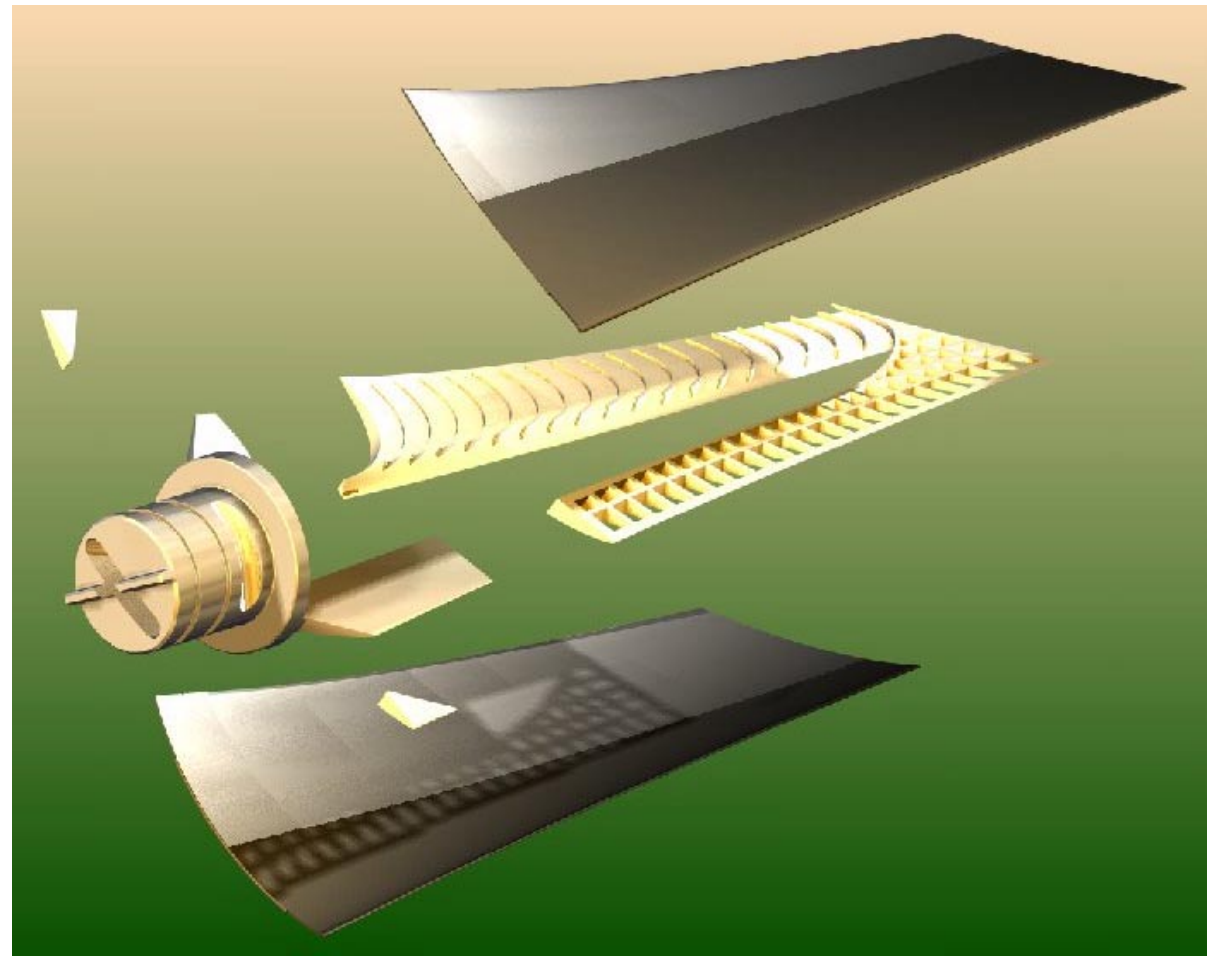

(b) Exploded view showing blade components.

Figure 2. Details of Composite Trailing Edge Rotor Blade 


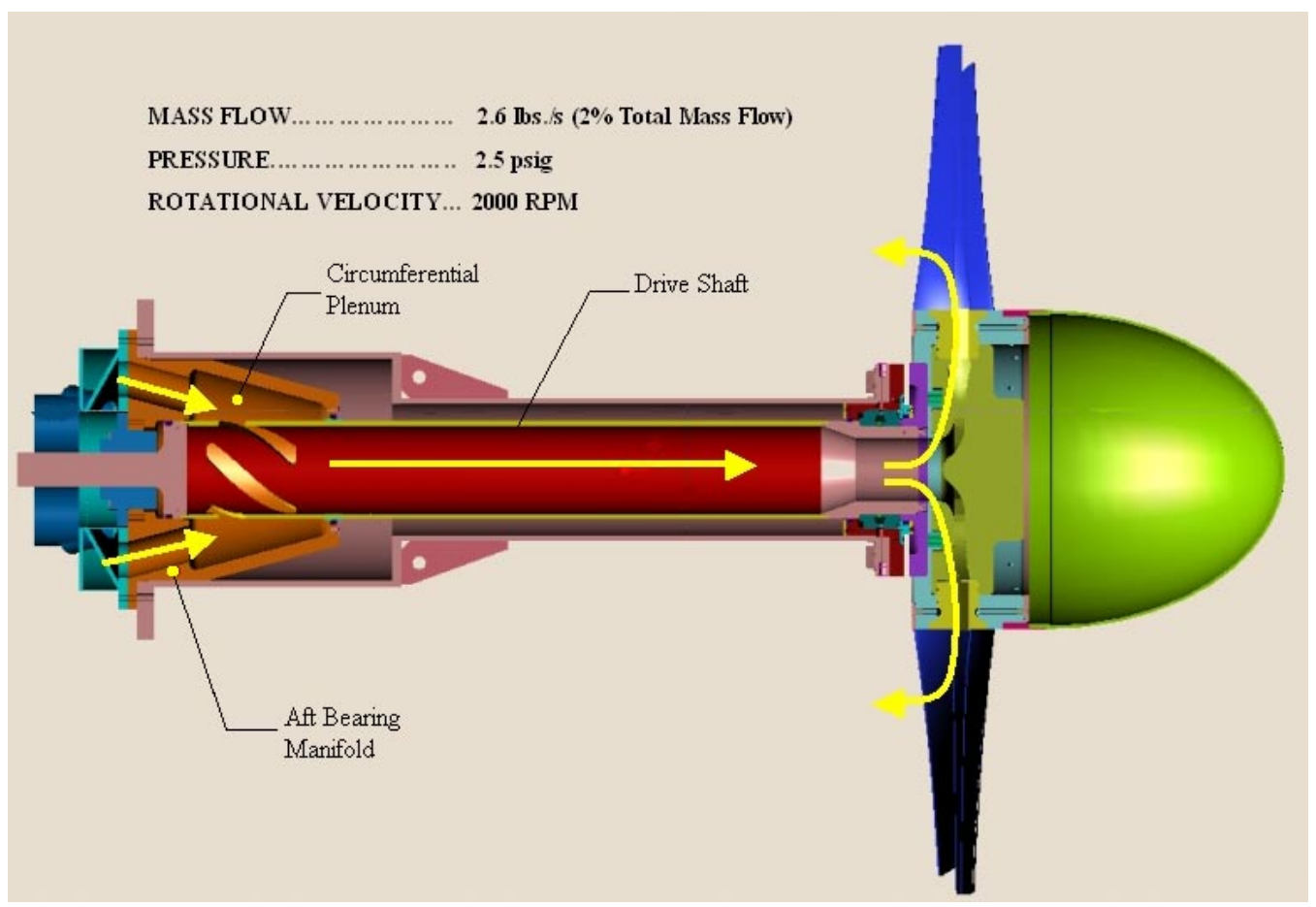

(a) Rotor/shaft assembly, yellow arrows indicate injection air supply

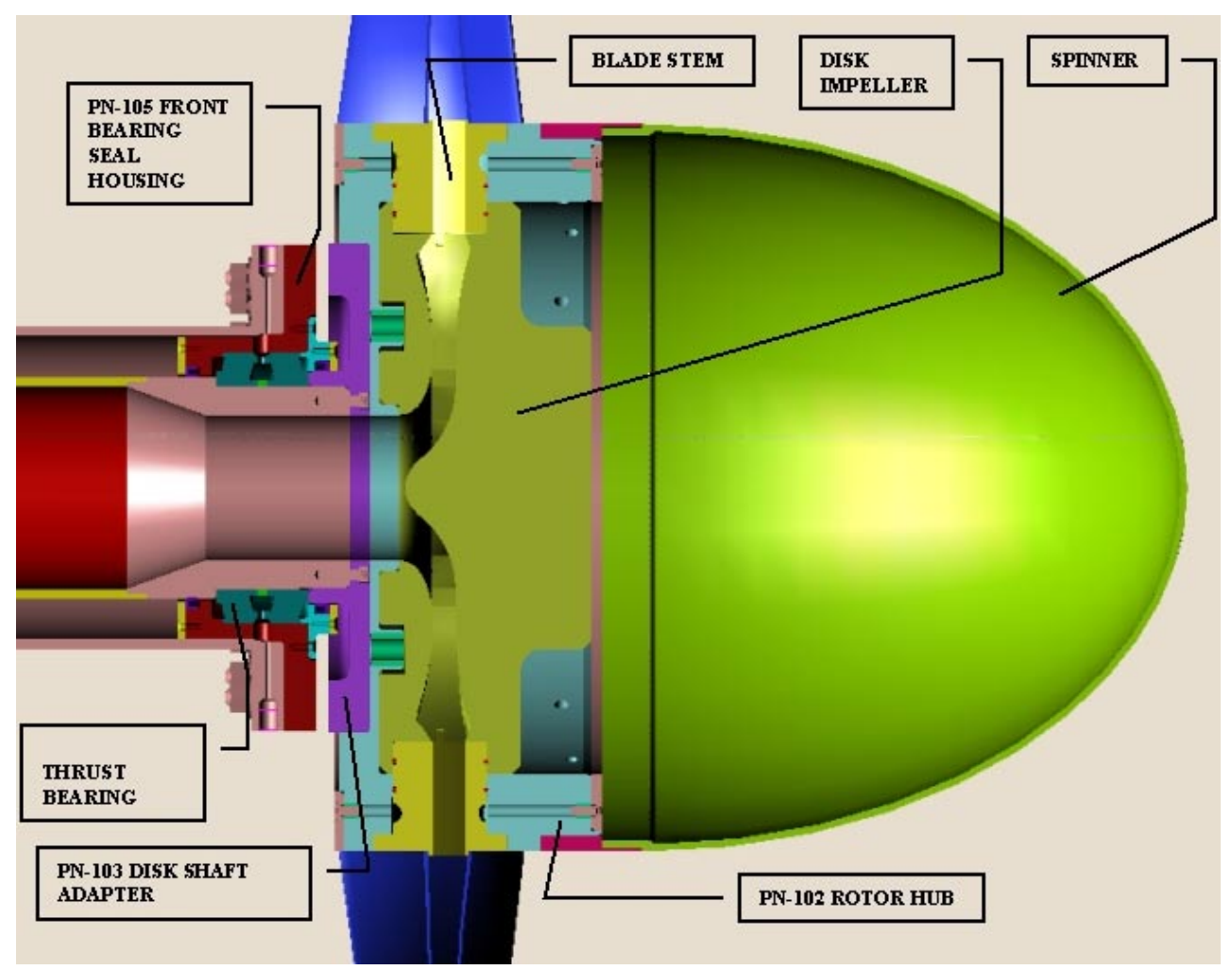

(b) Forward shaft components

Figure 3. Schematic of ANCF showing air delivery components 


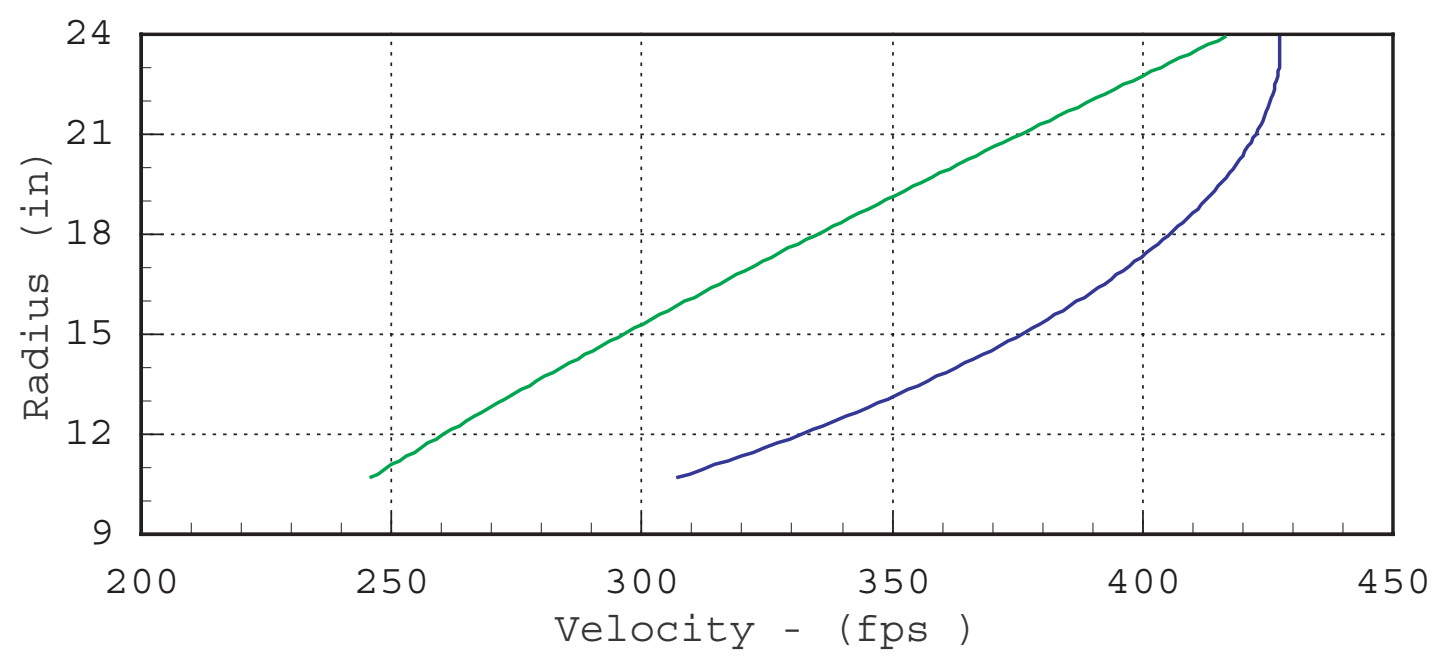

(a) Injection velocity as a function of span

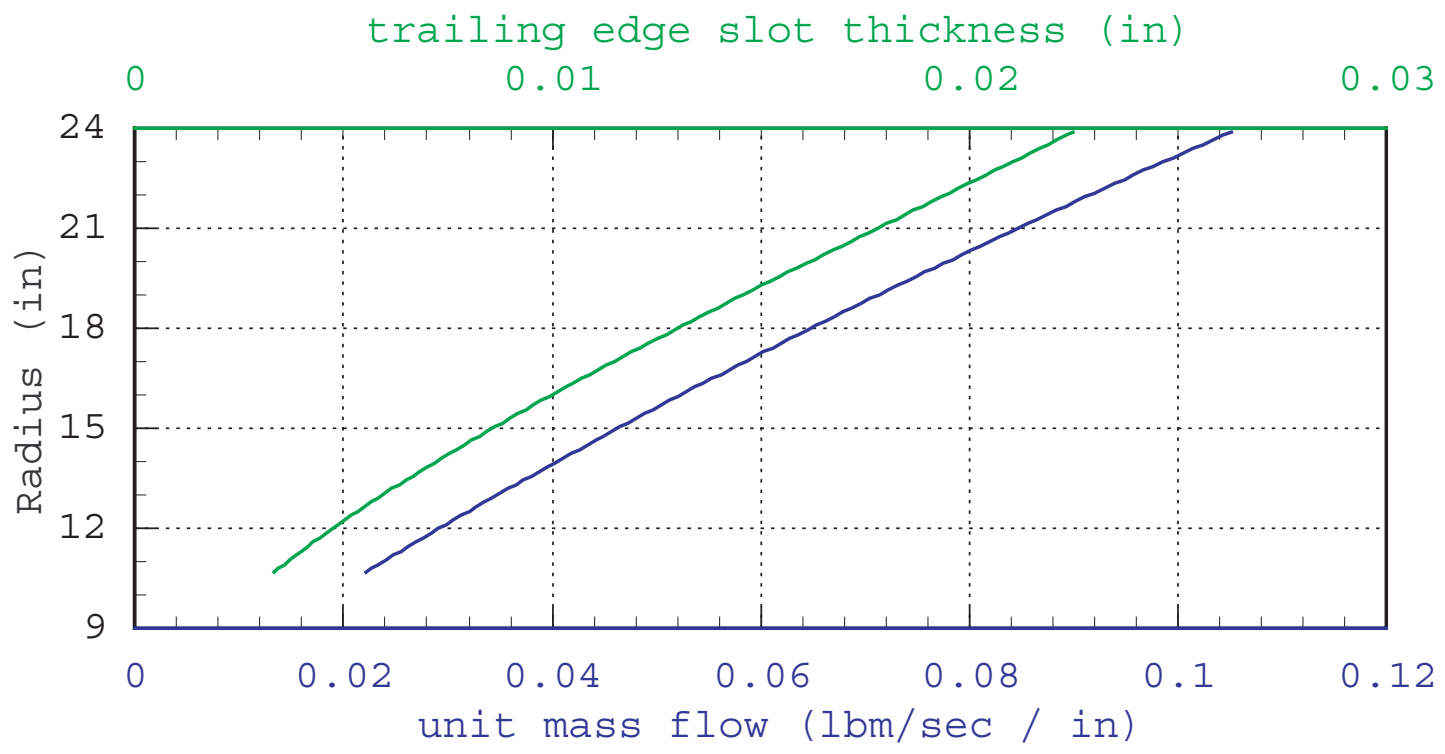

(b) Slot thickness and unit mass flow as a function of span

Figure 4. Trailing edge design parameters 


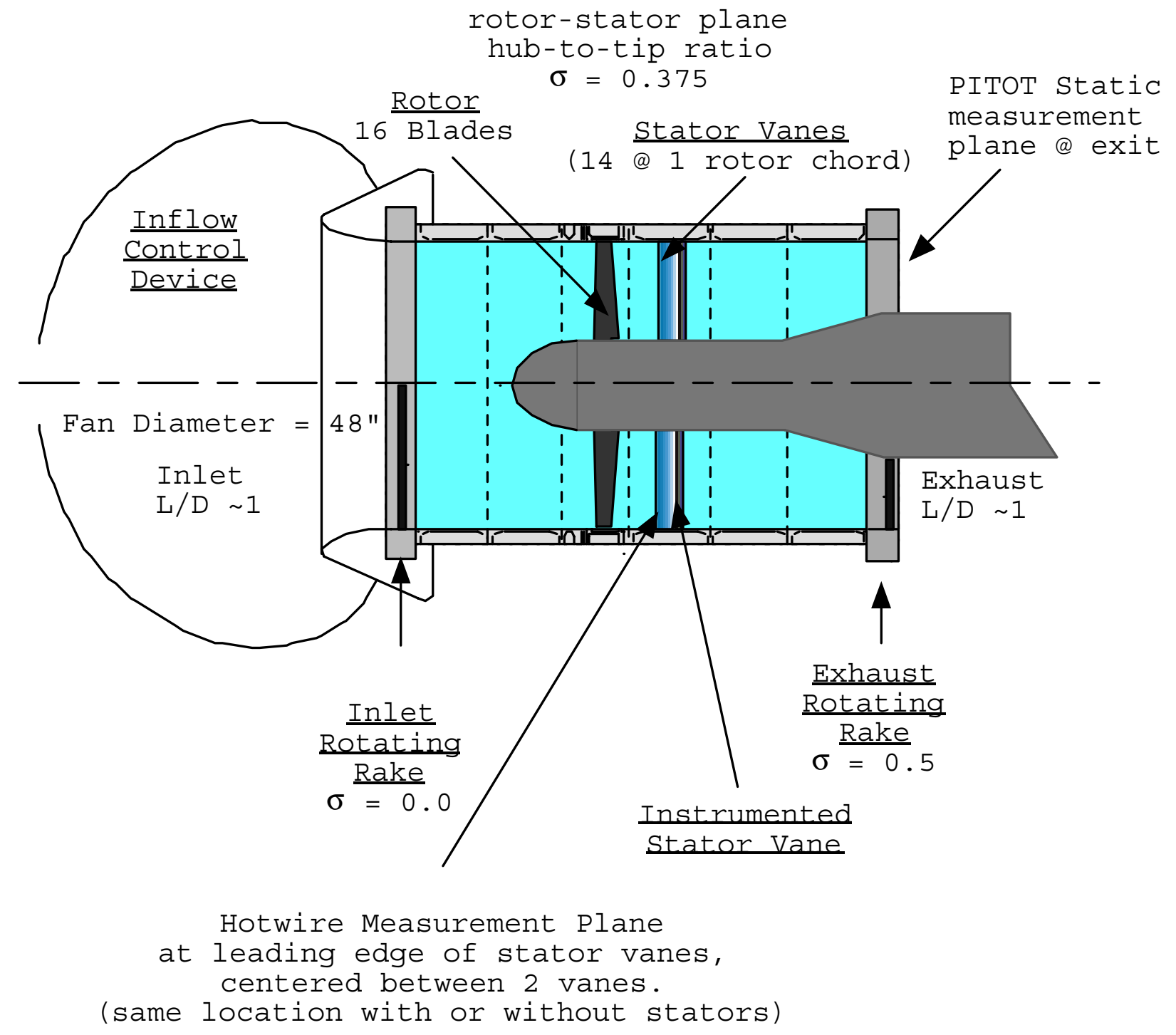

Figure 5. Schematic of ANCF showing measurement locations 

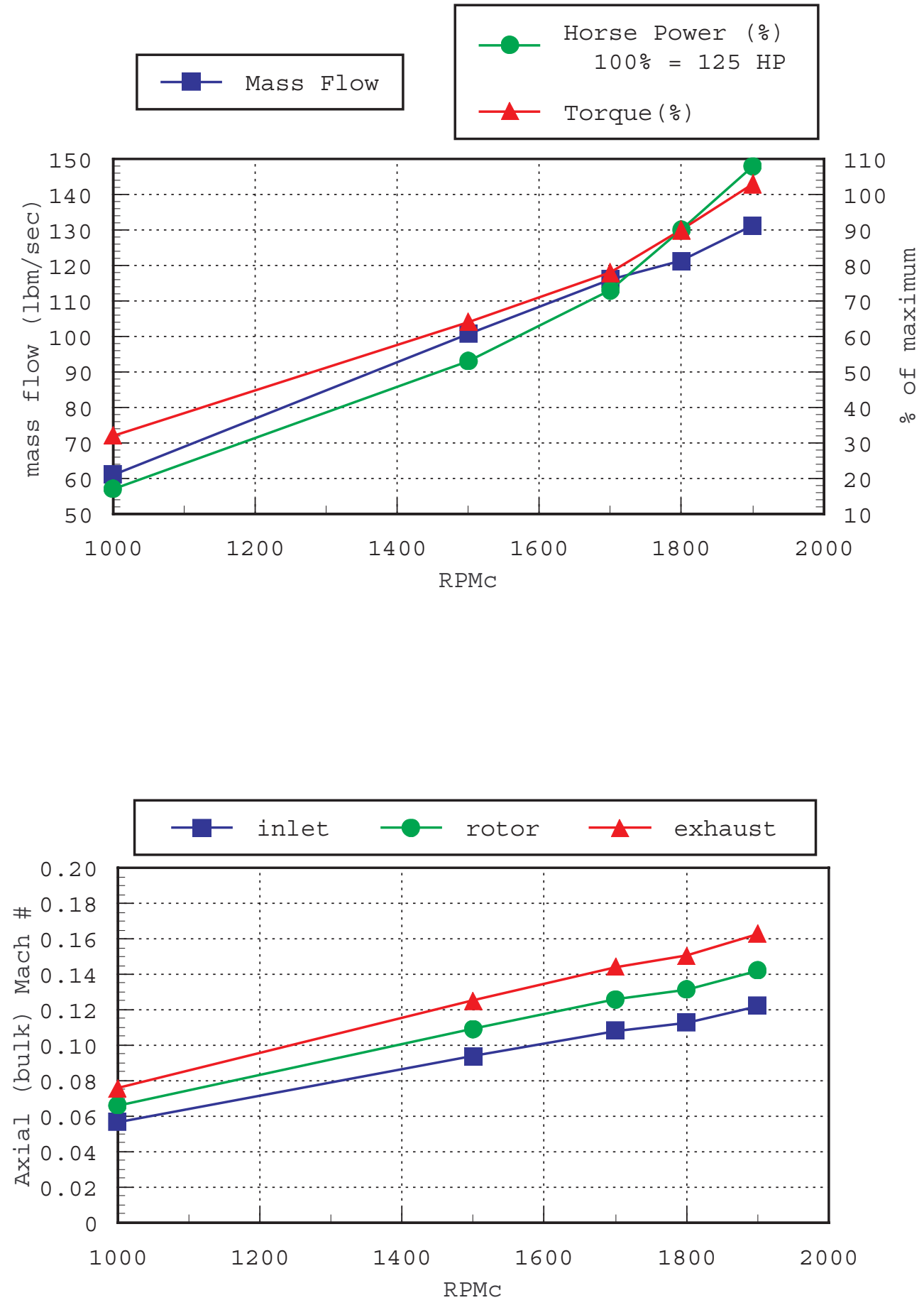

Figure 6. ANCF/TERB overall performance characteristics 


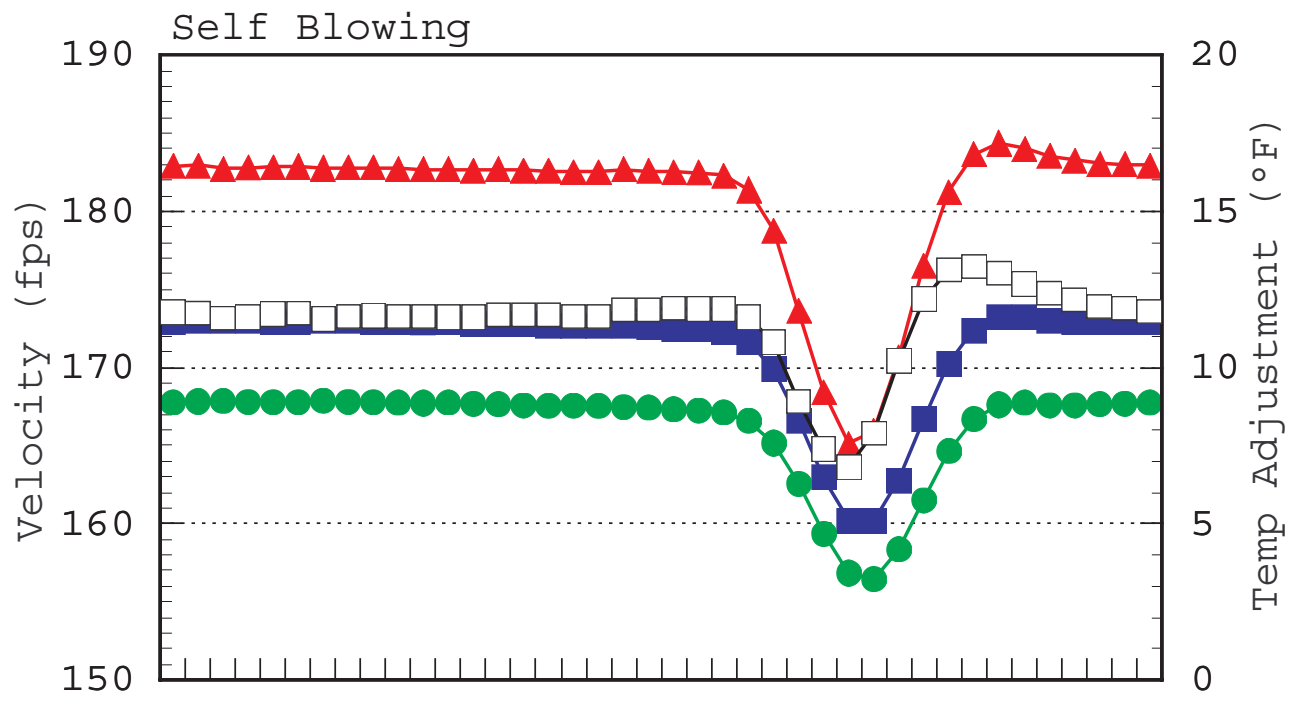

$$
\begin{aligned}
& - \text { Velocity @ High Overheat Ratio } \\
& - \text { Velocity @ Low Overheat Ratio } \\
& \rightarrow \text { Velocity from Convergence } \\
& -\square-\text { Temperature from Convergence }
\end{aligned}
$$

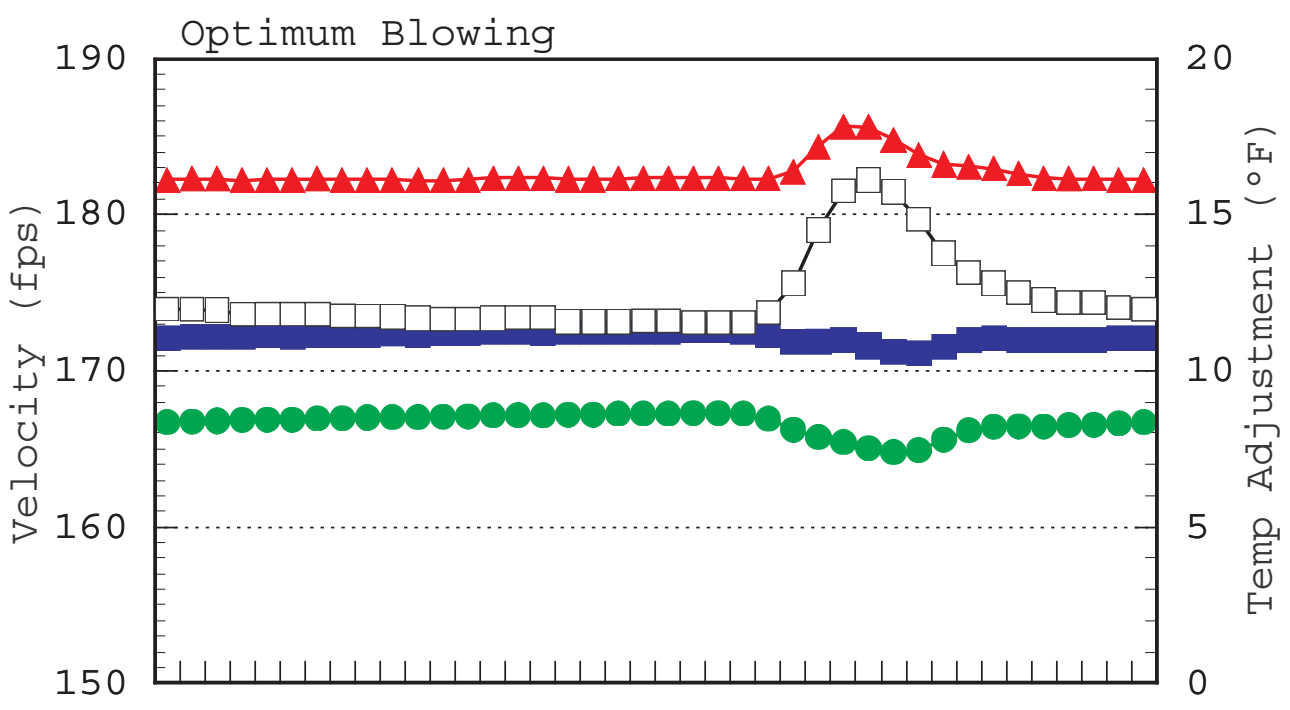

Figure 7. Comparison of passage averaged profiles with and without assumed temperature profile correction 

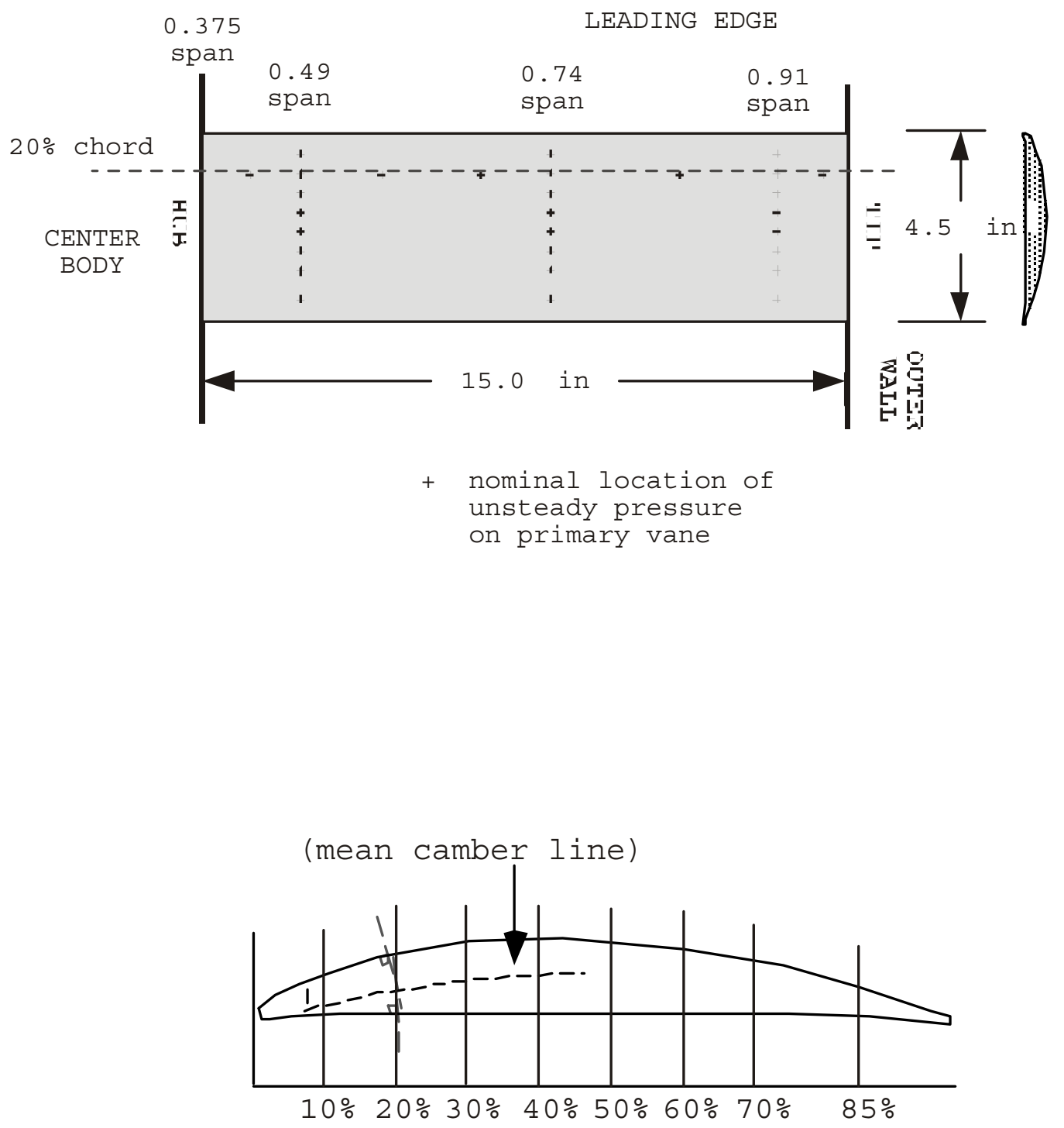

Figure 8. Instrumented stator vane pressure measurement locations 


\begin{tabular}{|c|c|c|c|c|c|c|c|c|}
\hline & 1BPF & $2 \mathrm{BPI}$ & & 3BPF & & & & \\
\hline \multirow{2}{*}{$\begin{array}{l}\text { MODE - - > } \\
(\mathrm{m}, \mathrm{n})\end{array}$} & $(2,0)$ & \multicolumn{2}{|c|}{$(4,0) \quad(4,1)$} & \multicolumn{2}{|c|}{$(6,0) \quad(6,1)$} & $(6,2)$ & $(-8,0)$ & $8,1)$ \\
\hline & 1018 & 887 & 1547 & 833 & 1304 & 1696 & 1072 & 1568 \\
\hline EXHAUST & 894 & 863 & 1473 & 829 & 1247 & 1709 & 1071 & 1533 \\
\hline
\end{tabular}

Figure 9. Modal characteristics

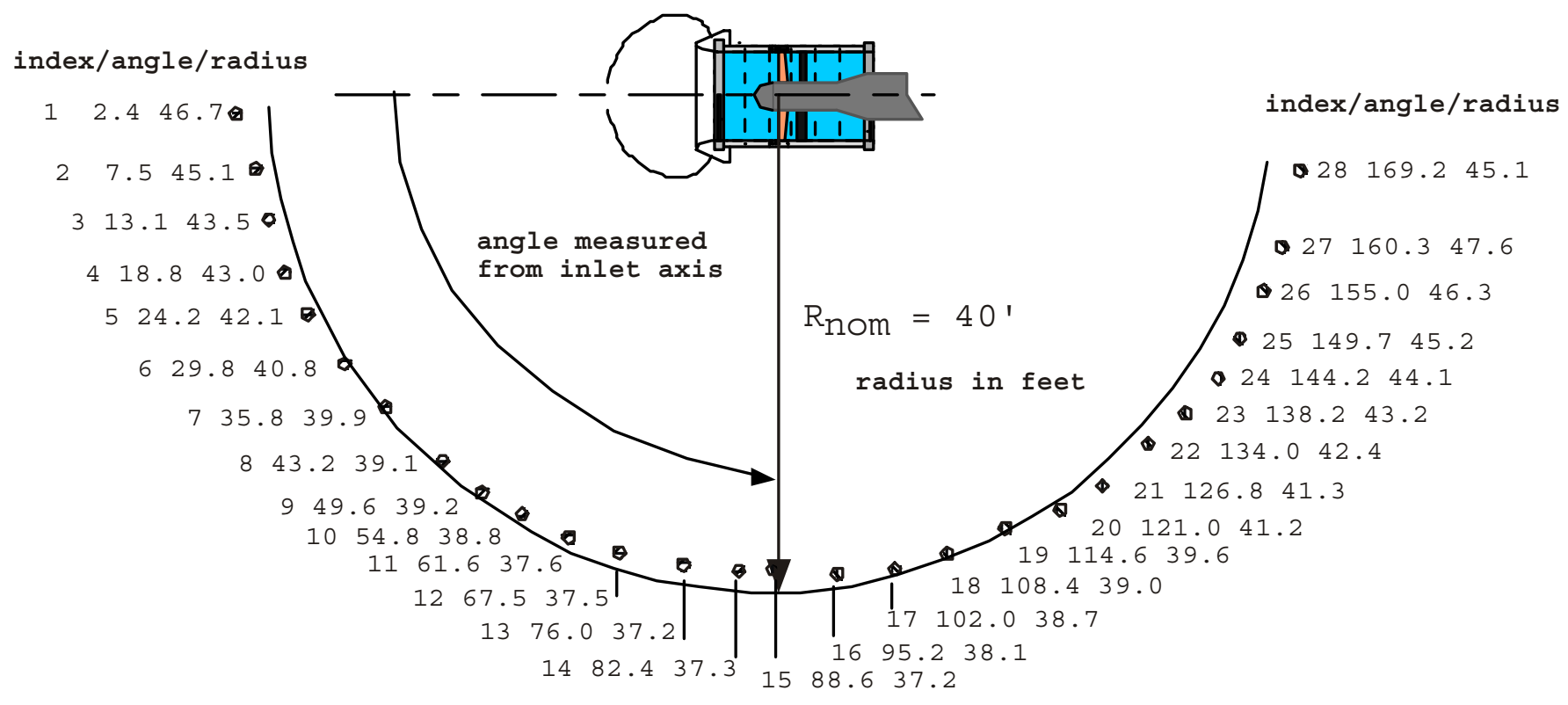

Figure 10. Farfield arena microphone locations 


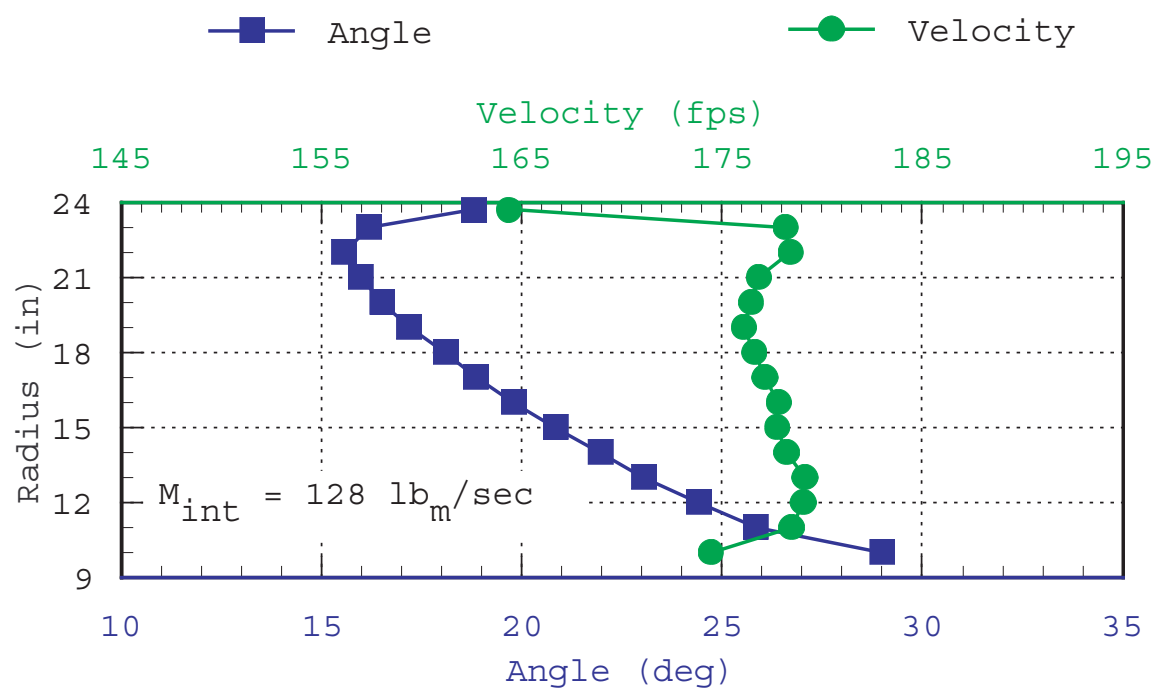

(a) Trailing Edge Inserts (no blowing)
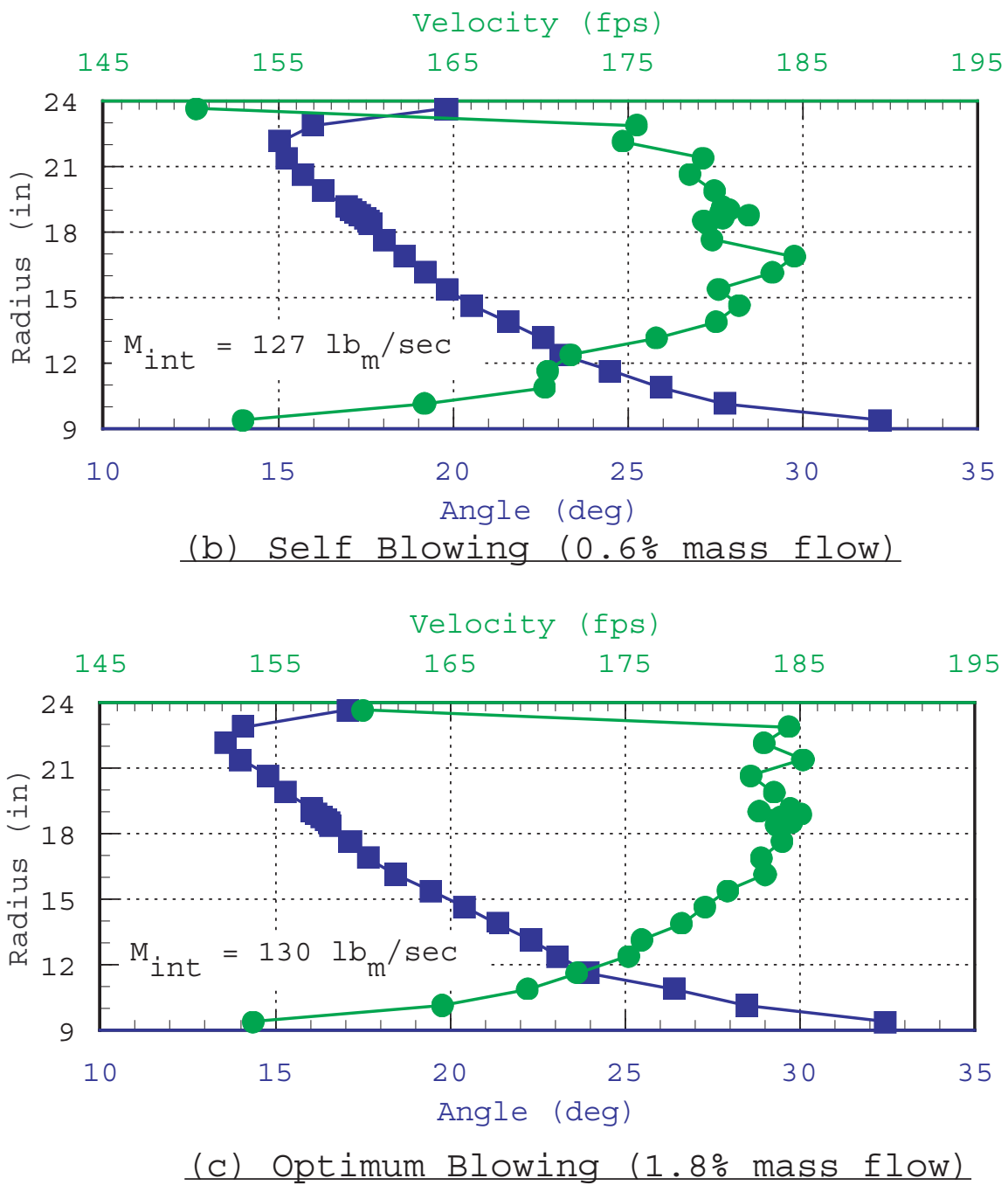

Figure 11. Circumferentially averaged mean flow values measured by hotwire 

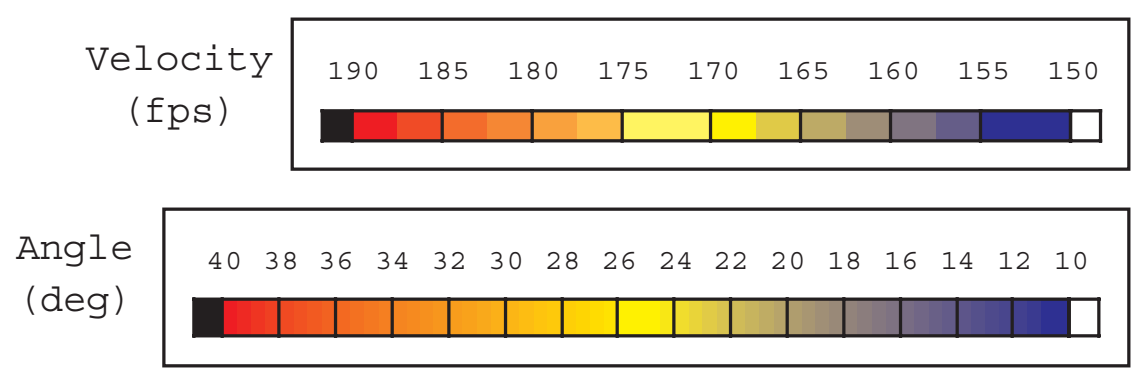

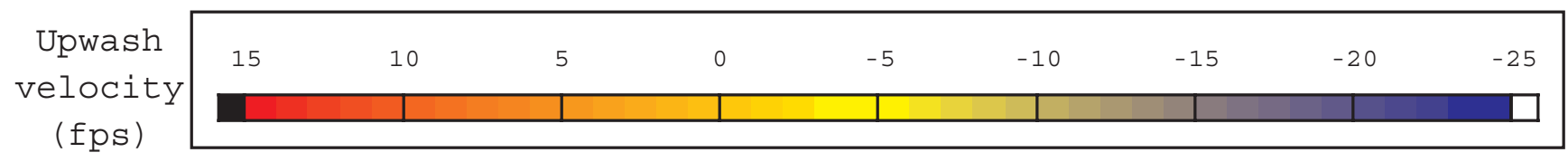

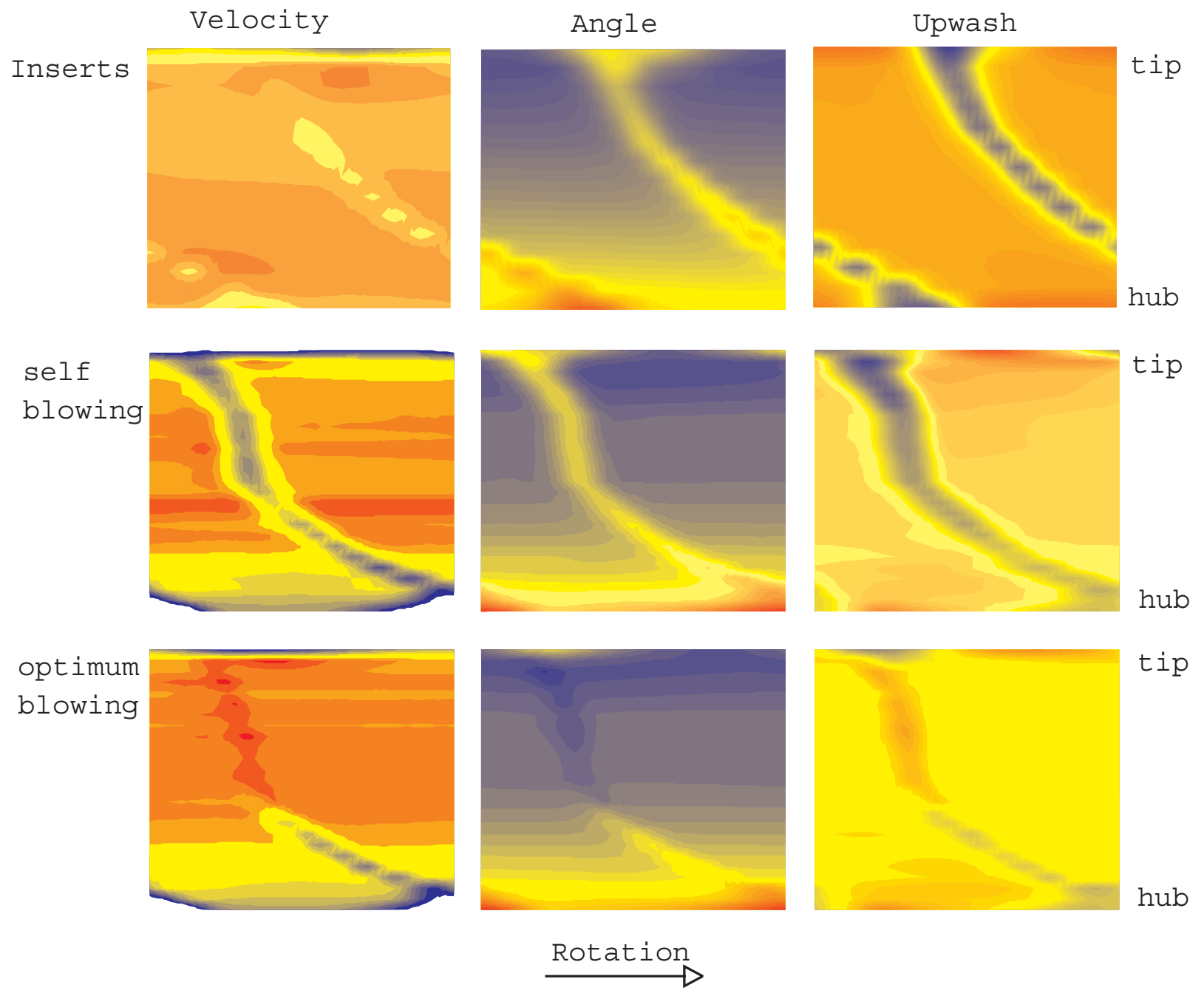

Figure 12. Passage averaged flow values contour plots at measurement plane downstream of fan 


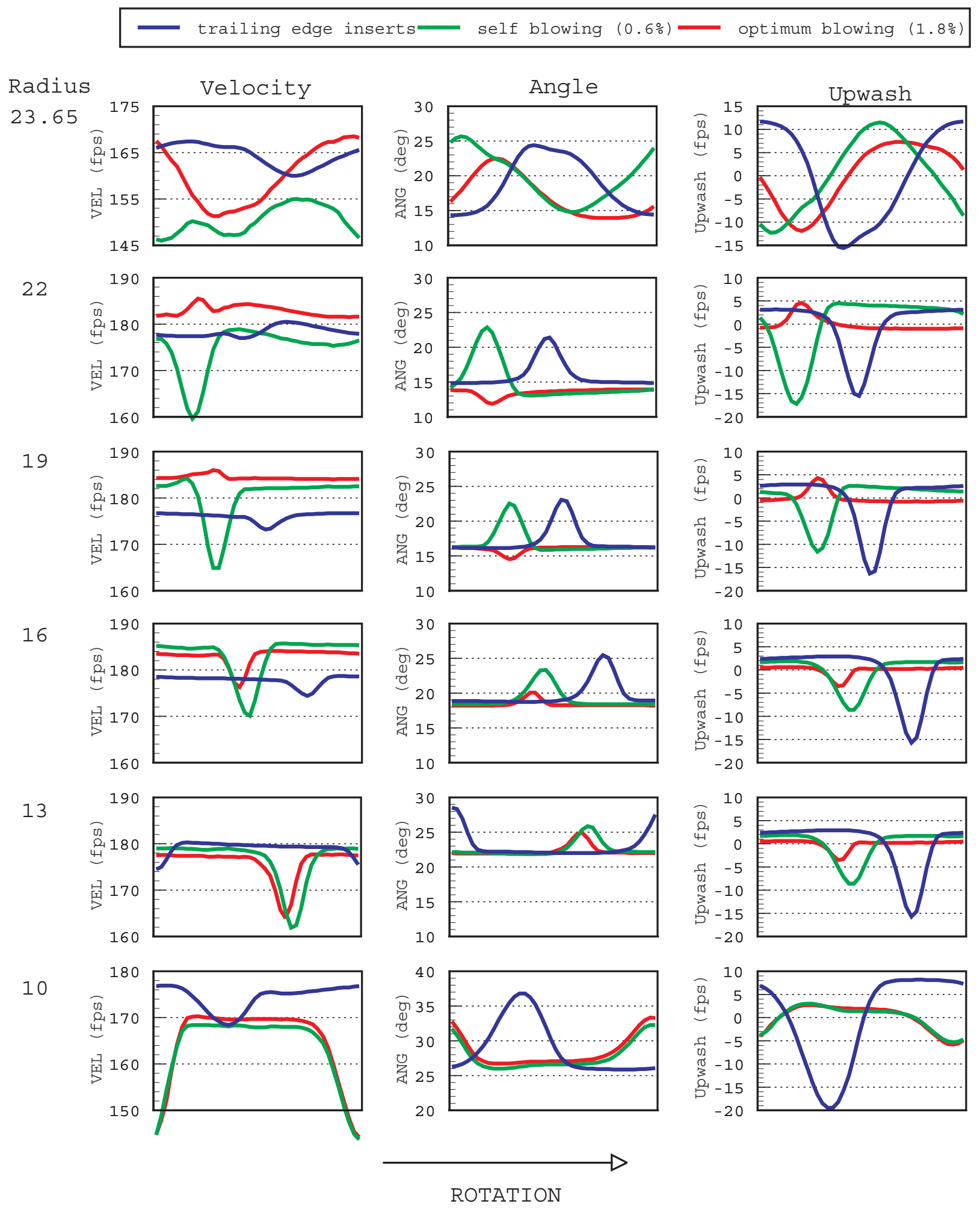

Figure 13. Passage averaged flow values at selected radial locations 


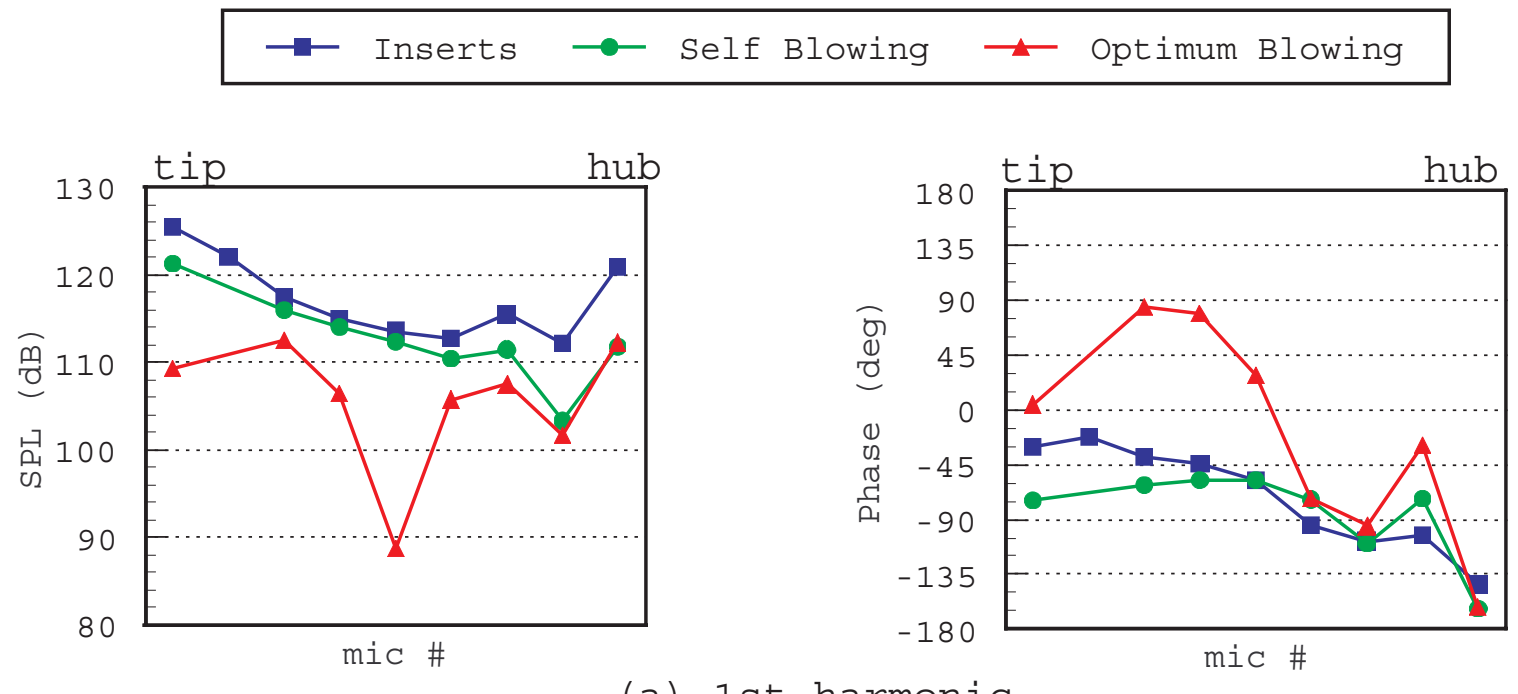

(a) 1st harmonic
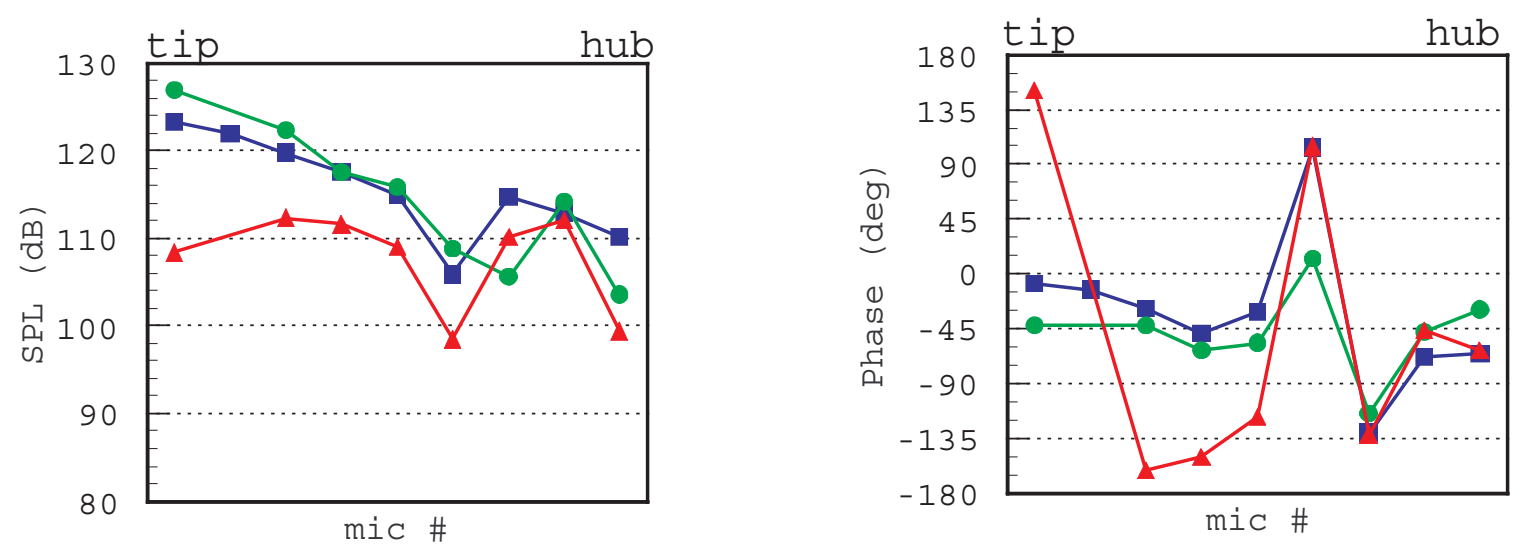

(b) 2nd harmonic

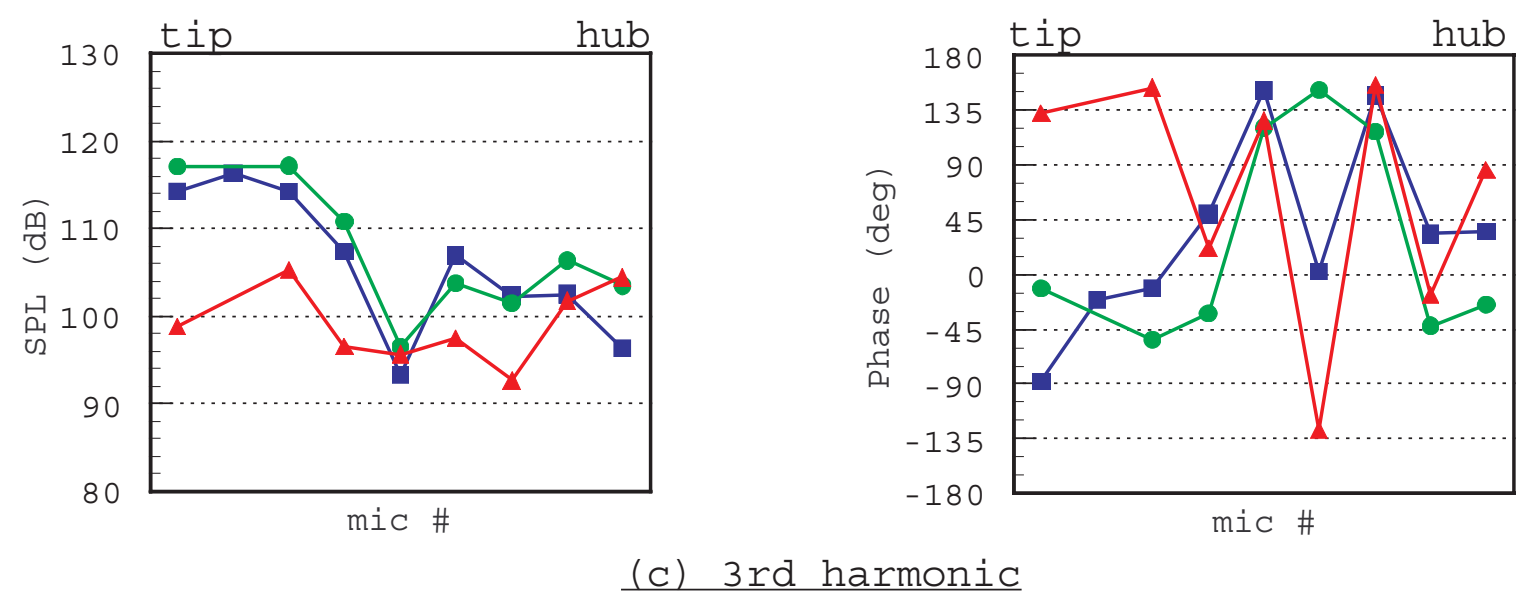

Figure 14. Stator vane suction surface unsteady pressures along $20 \%$ chord 

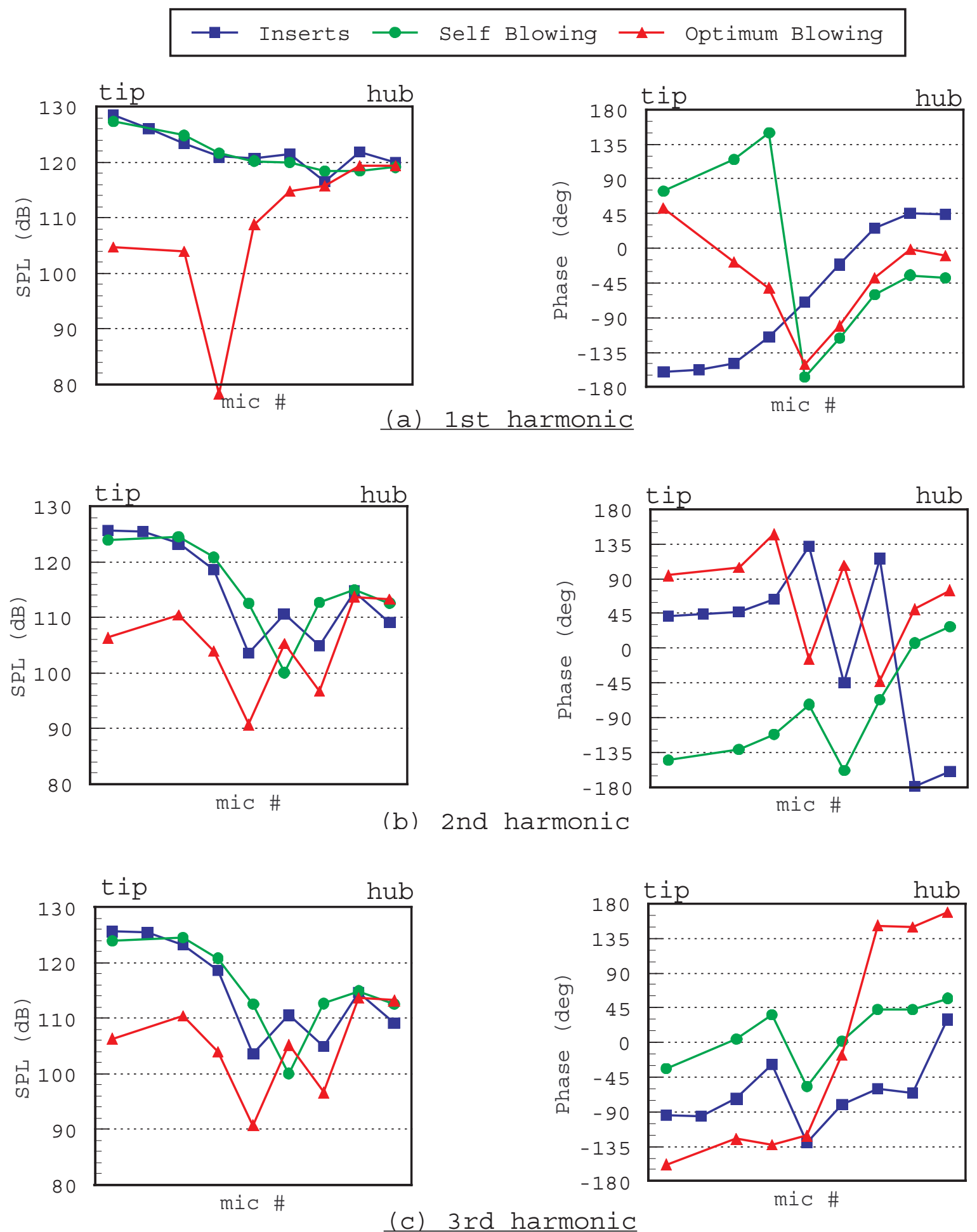

Figure 15. Stator vane pressure surface unsteady pressures along $20 \%$ chord 


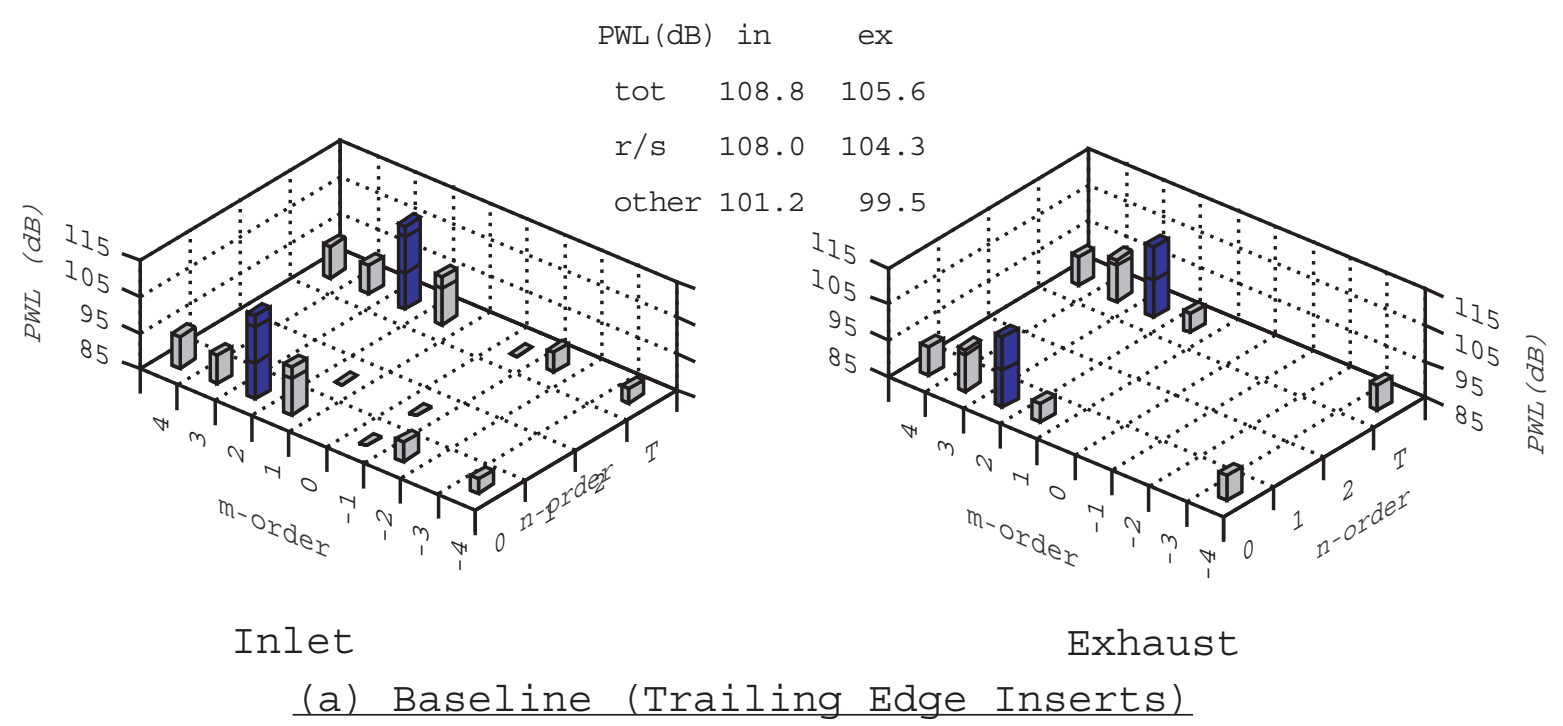

NOTE :

rotor-stator (r/s)

interaction modes shaded in blue

not taken

$\begin{array}{ccr}\text { PWL }(\mathrm{dB}) & \text { in } & \text { ex } \\ \text { tot } & --- & 99.3 \\ \mathrm{r} / \mathrm{s} & --- & 99.3\end{array}$

Inlet

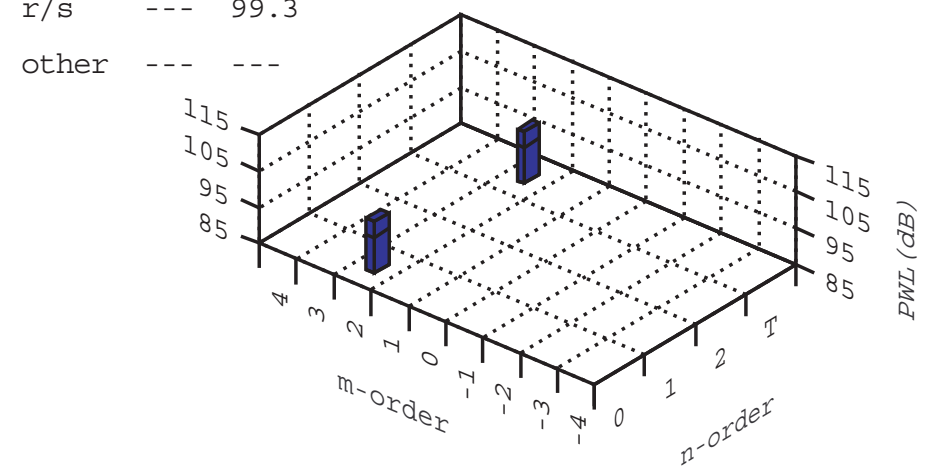

Exhaust

(b) Self Blowing (0.6\%)

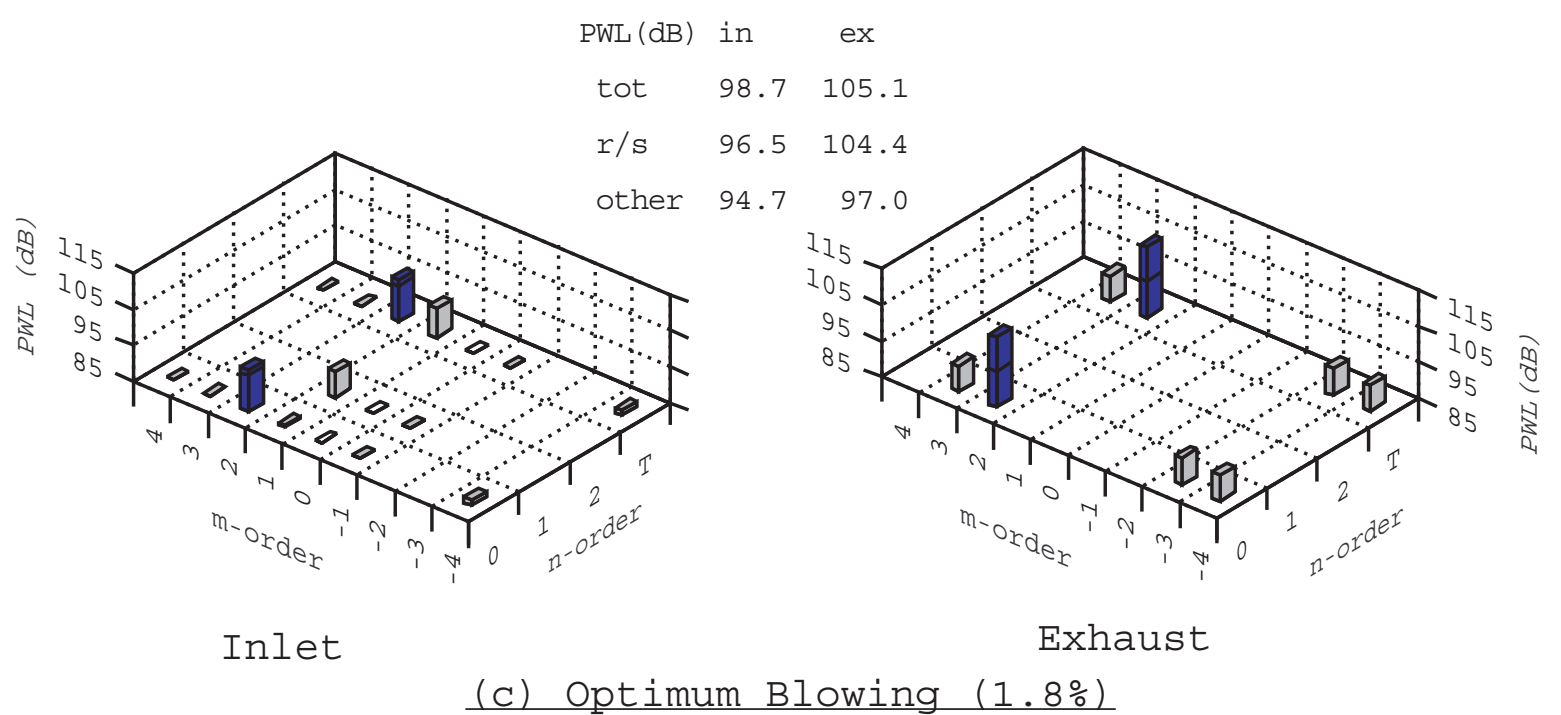

Figure 16. Modal structure at $1 \mathrm{xBPF}$ with and without blowing 


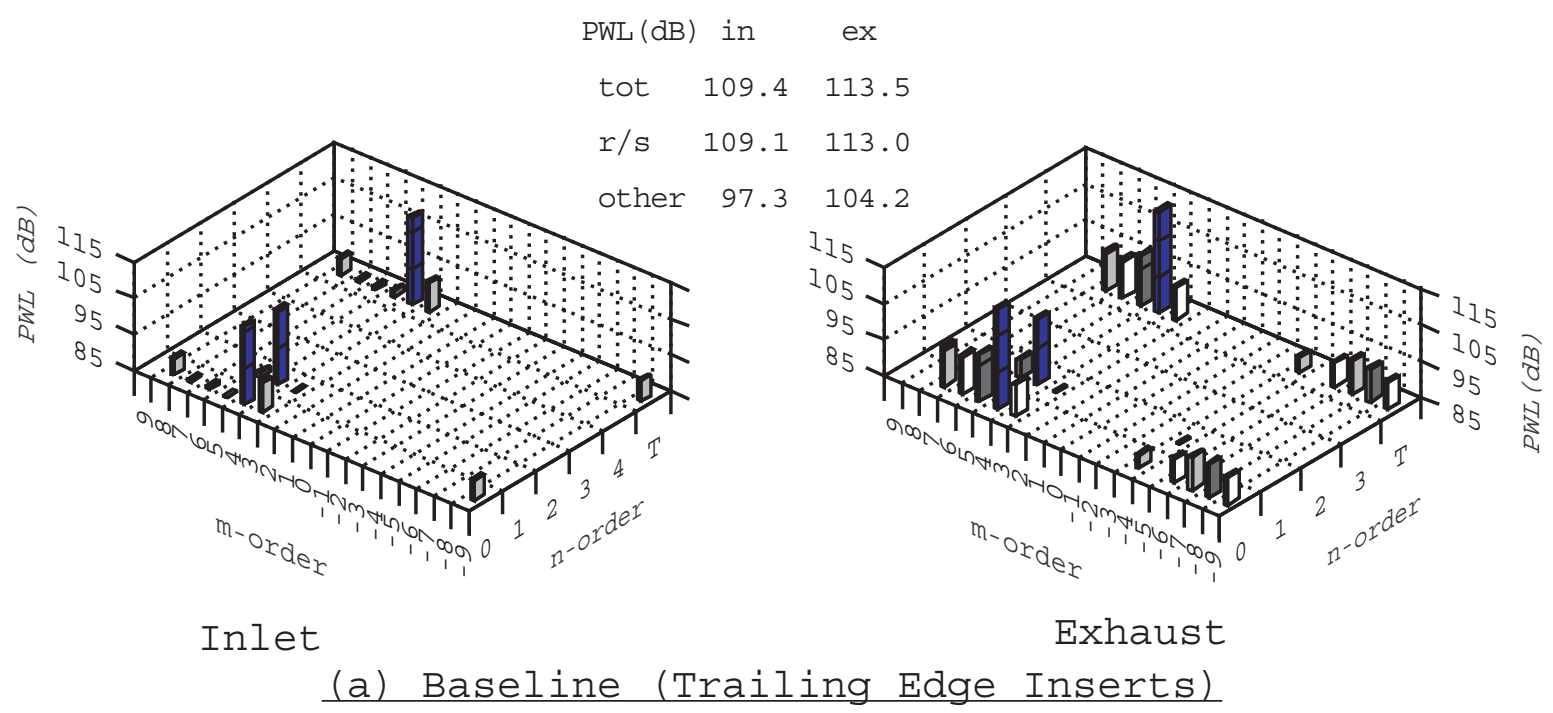

NOTE :

rotor-stator ( $r / s)$

interaction modes shaded in blue

not taken

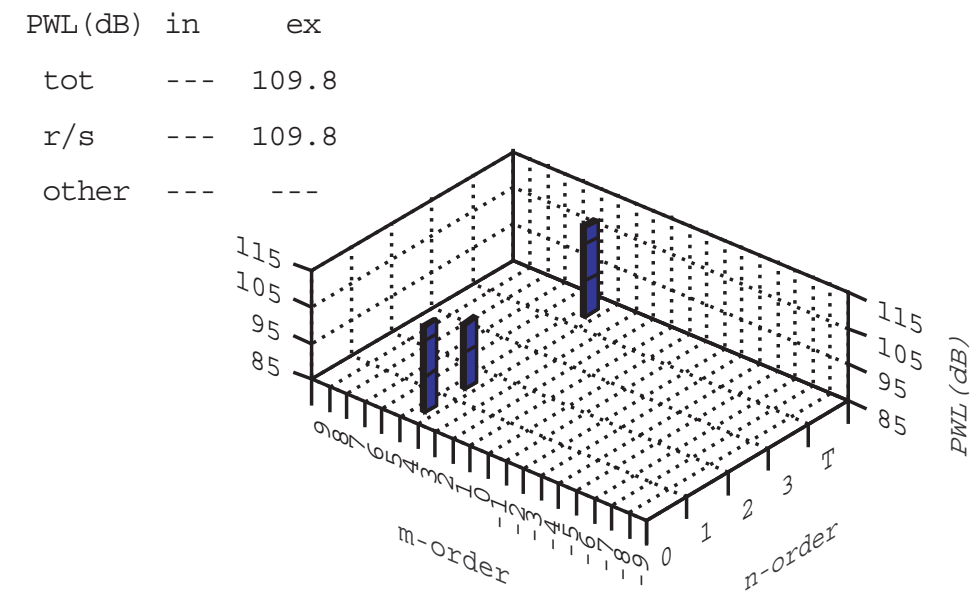

Inlet

Exhaust

(b) Self Blowing (0.6\%)

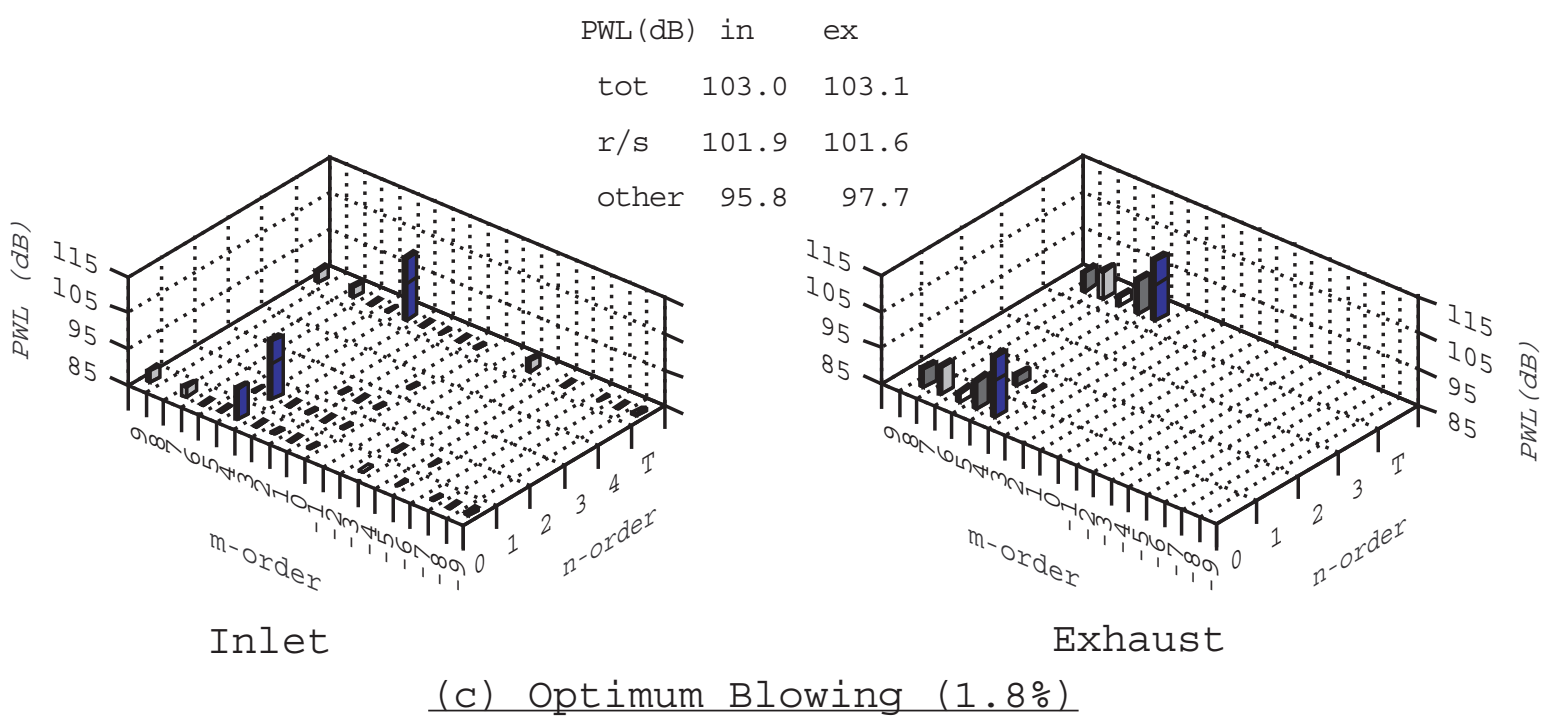

Figure 17. Modal structure at 2xBPF with and without blowing 


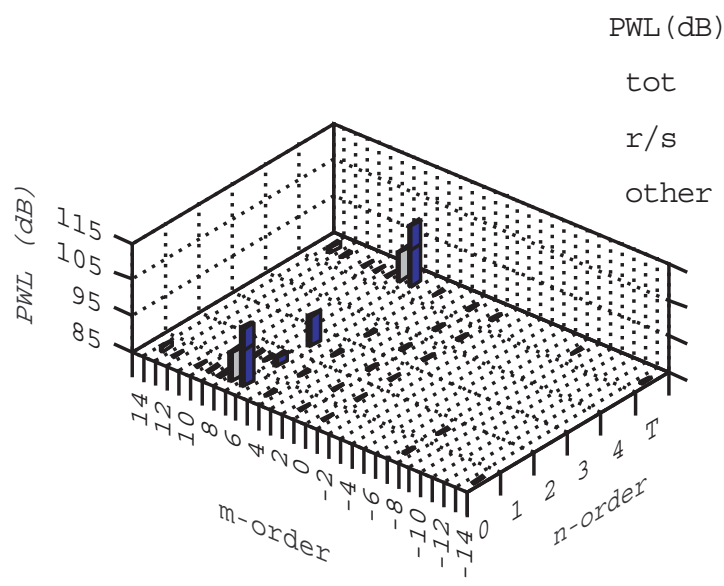

Inlet ex

102.8112 .6

101.8111 .9

96.0104 .1

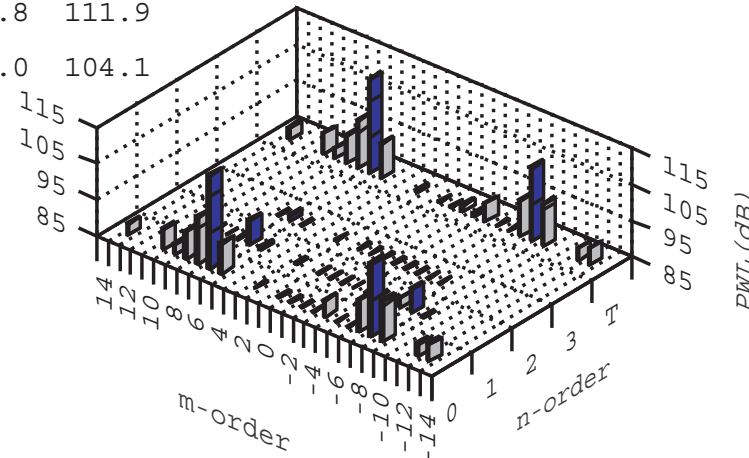

Exhaust

(a) Baseline (Trailing Edge Inserts)

NOTE :

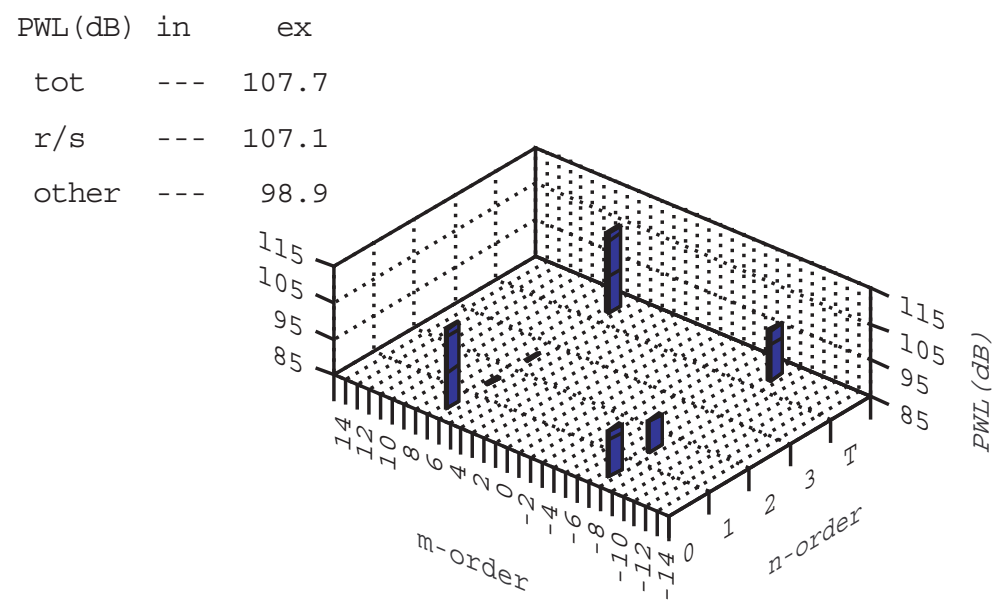

not taken

Inlet

Exhaust

(b) Self Blowing $(0.6 \%)$

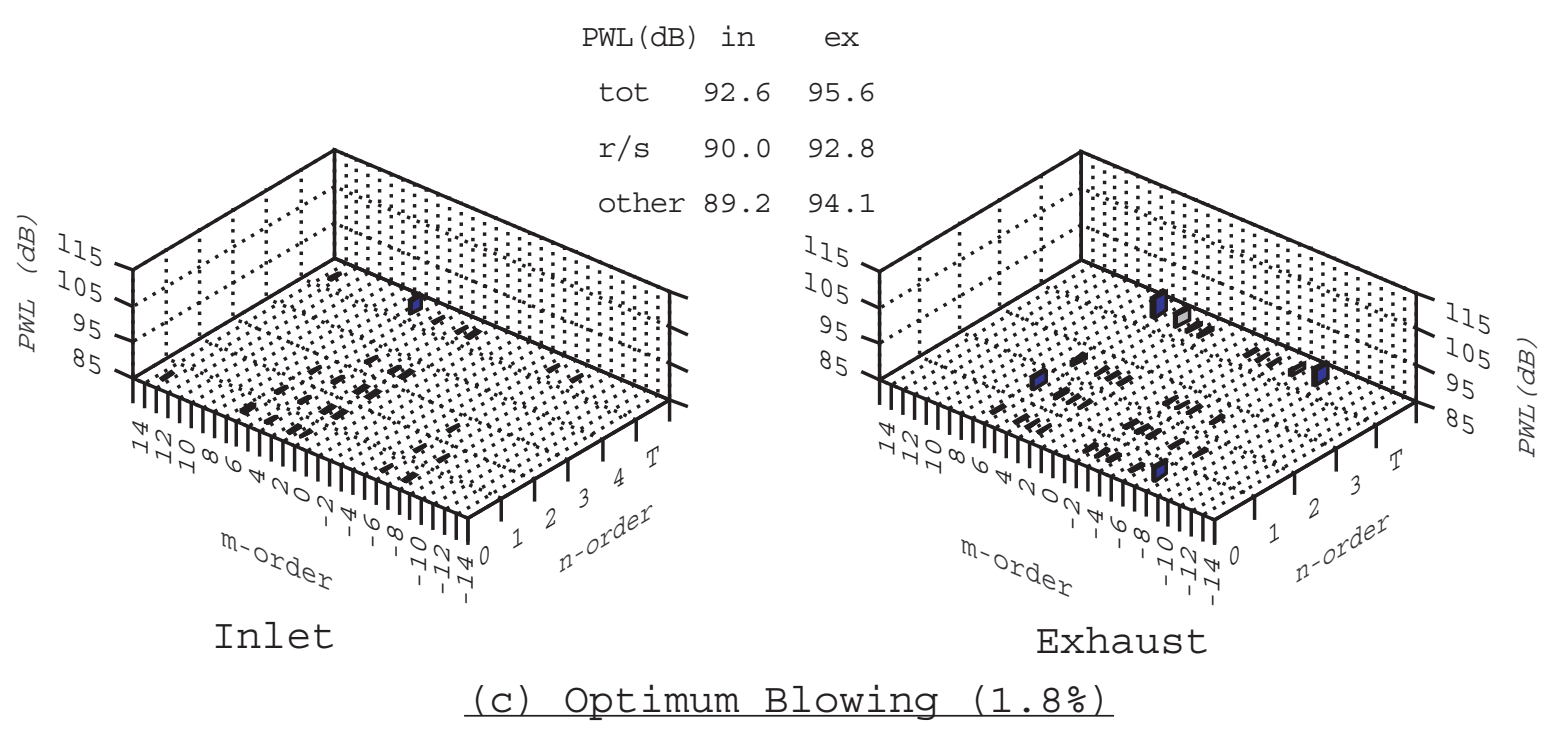

Figure 18. Modal structure at 3xBPF with and without blowing 


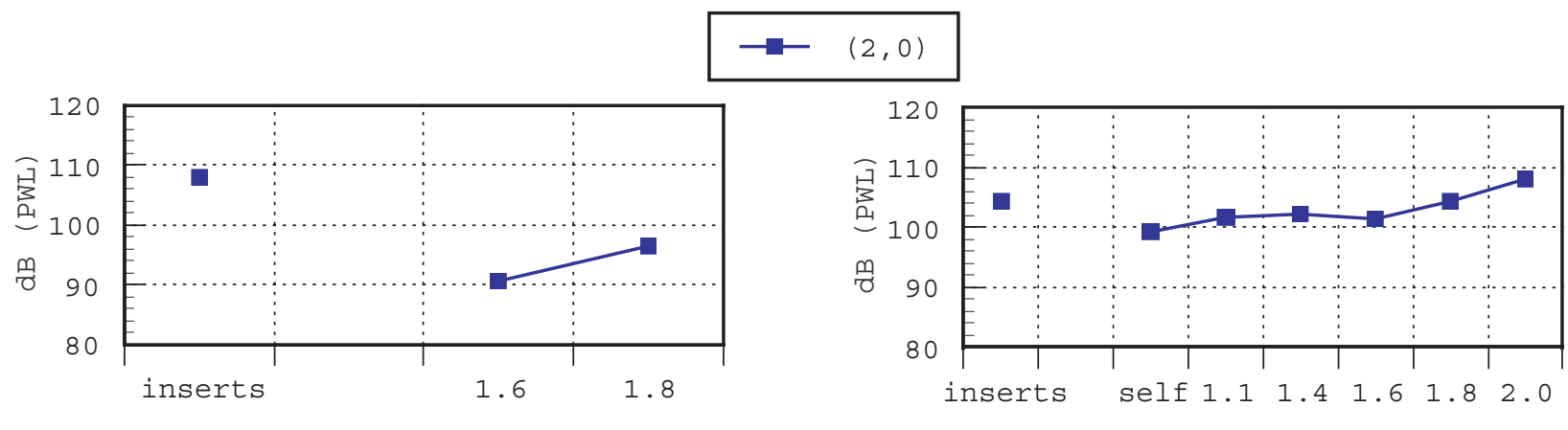

(a) $1 \mathrm{BPF}$
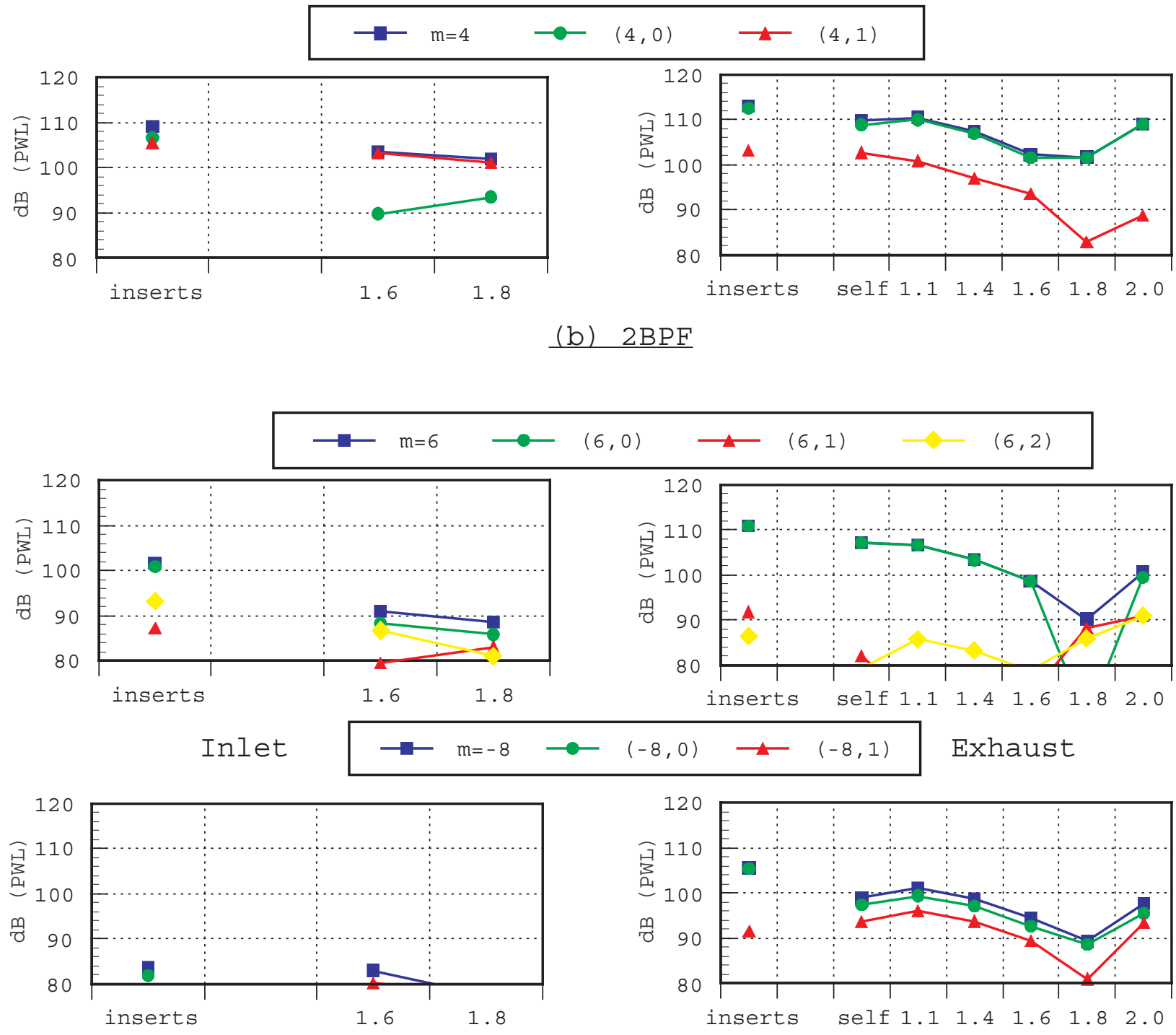

(c) $3 \mathrm{BPF}$

Figure 19. Rotor-stator interaction mode levels as a function of blowing rate (@1800 rpmc) 


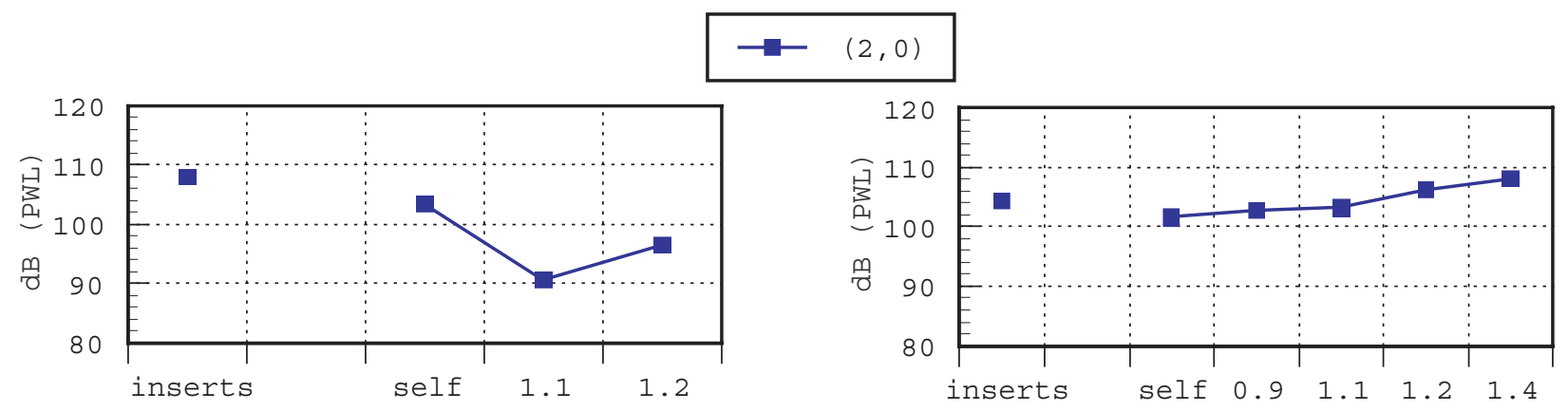

(a) $1 \mathrm{BPF}$
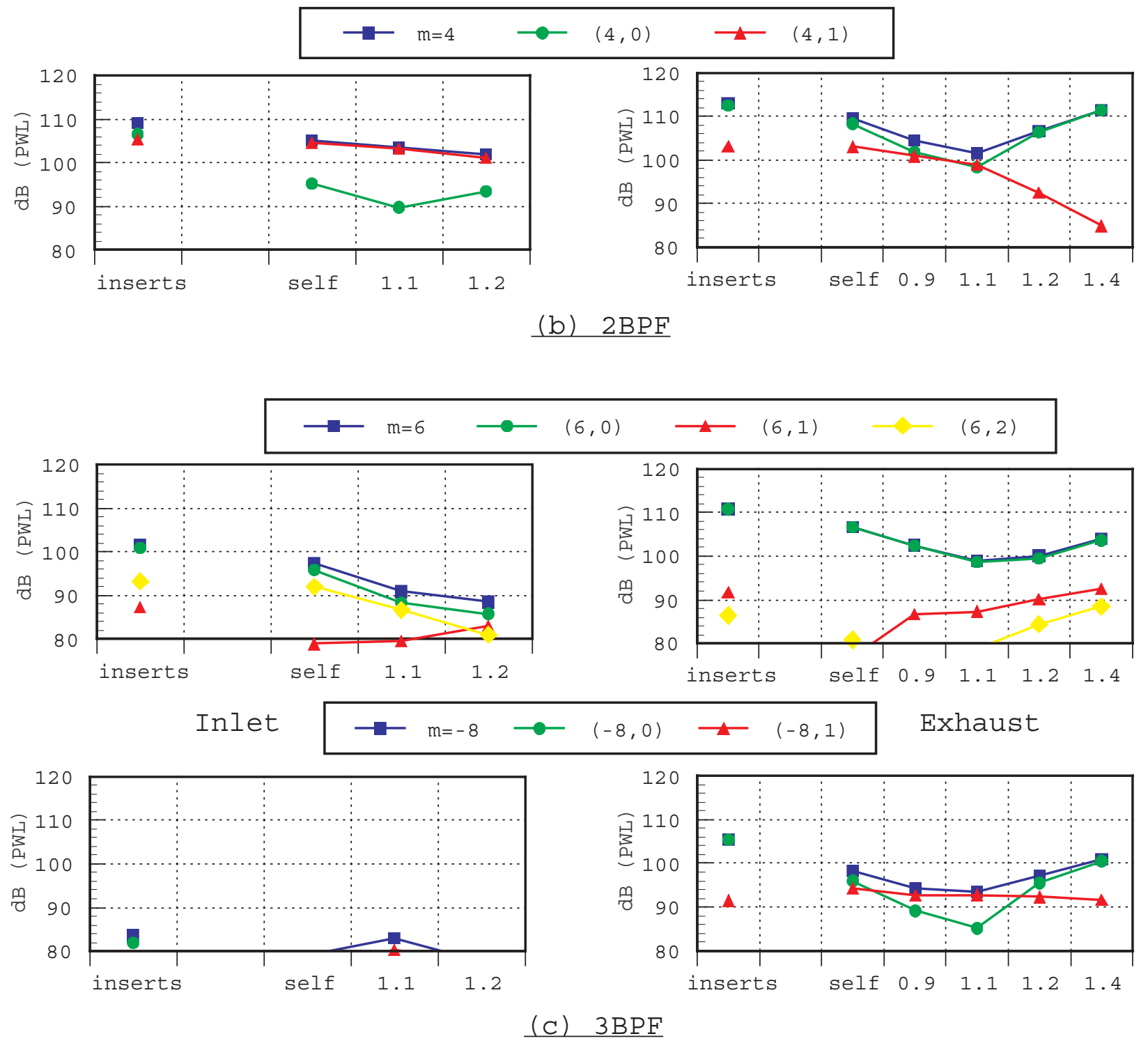

Figure 20. Rotor-stator interaction mode levels as a function of blowing rate (@1800 rpmc) blowing at 20\% tip only 

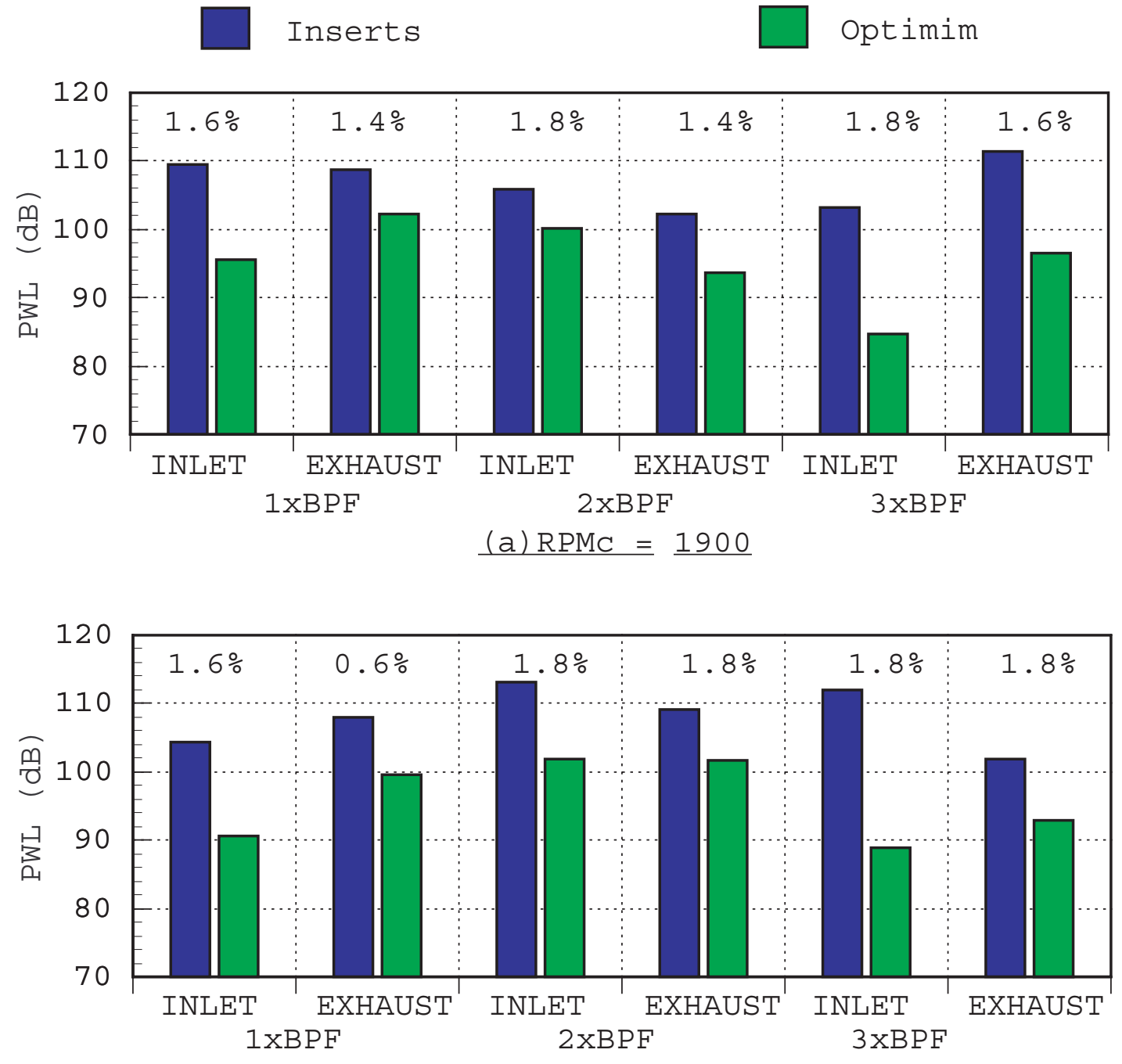

(b) $\mathrm{RPMC}=\underline{1800}$

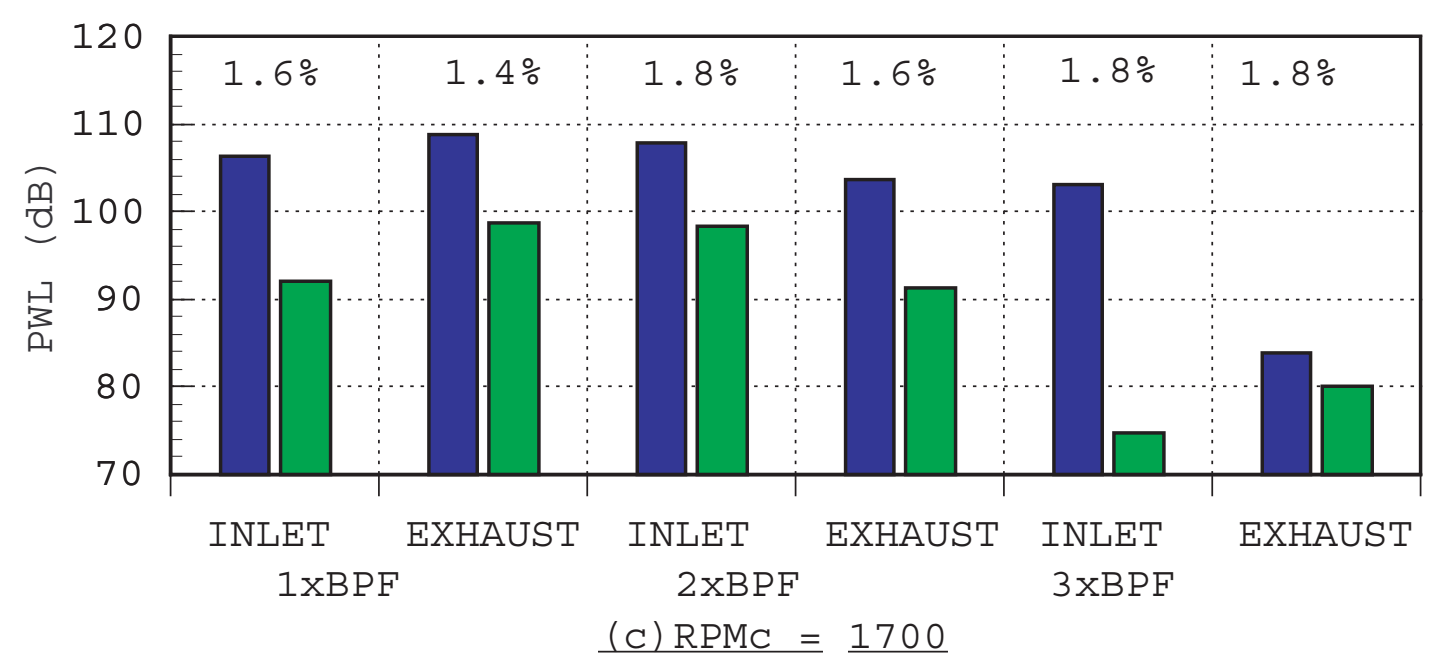

Figure 21. Maximum reductions obtained by blowing, several RPM 


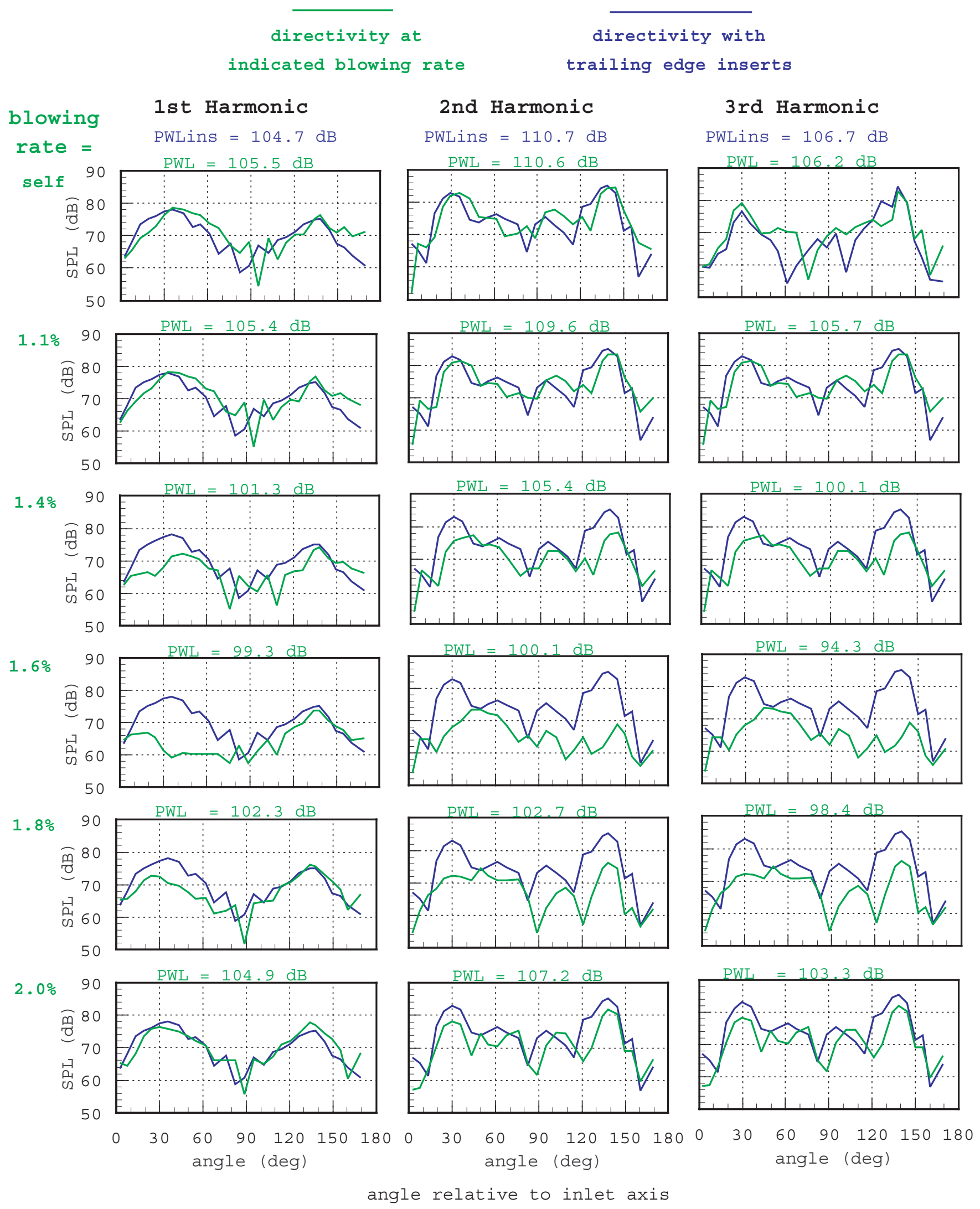

Figure 22. Farfield tonal directivity @ 1800 rpmc for various blowing rates compared to rotor with inserts 


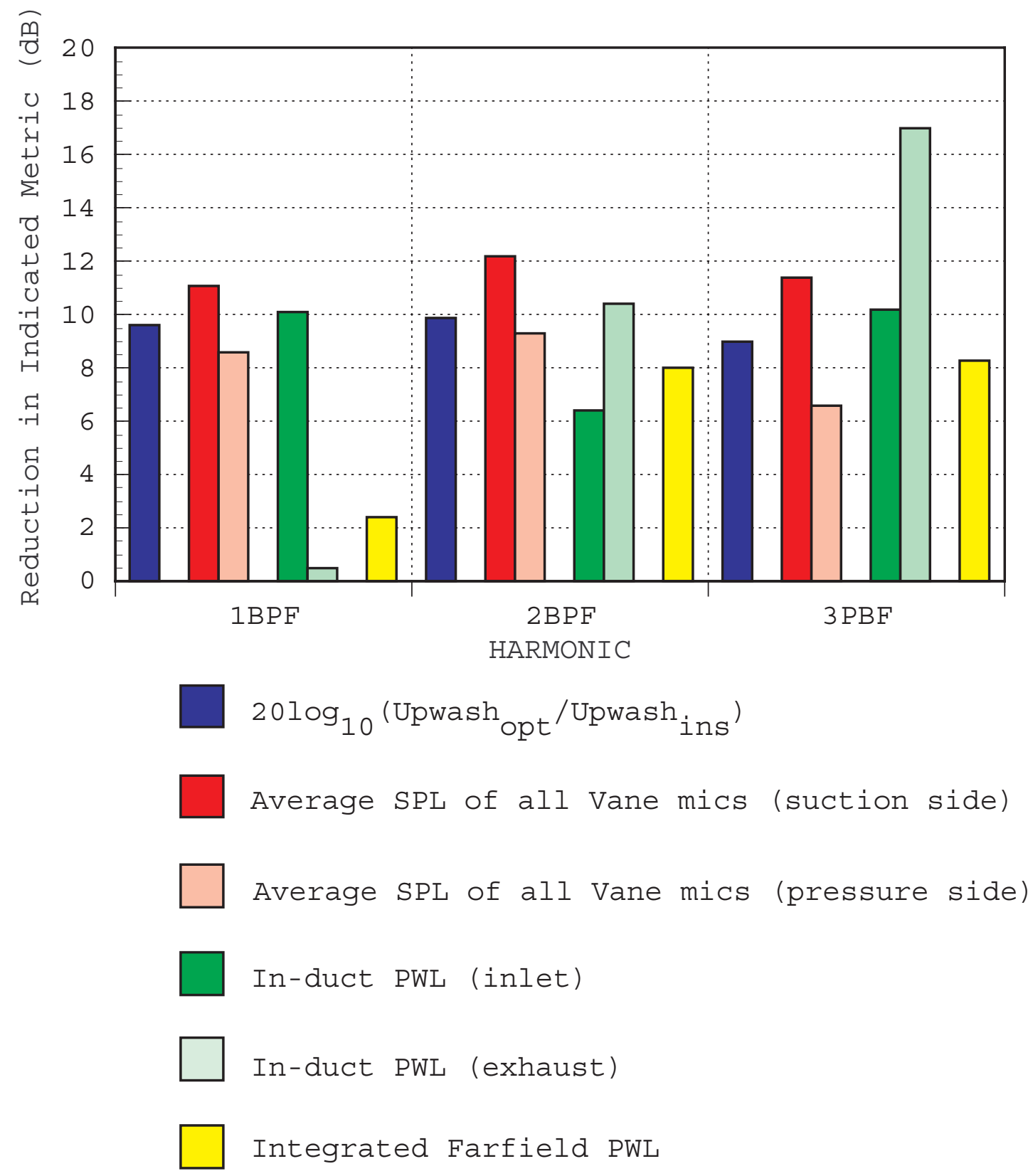

Figure 23. Comparison of reduction obtained with optimum blowing using various measurement methods 


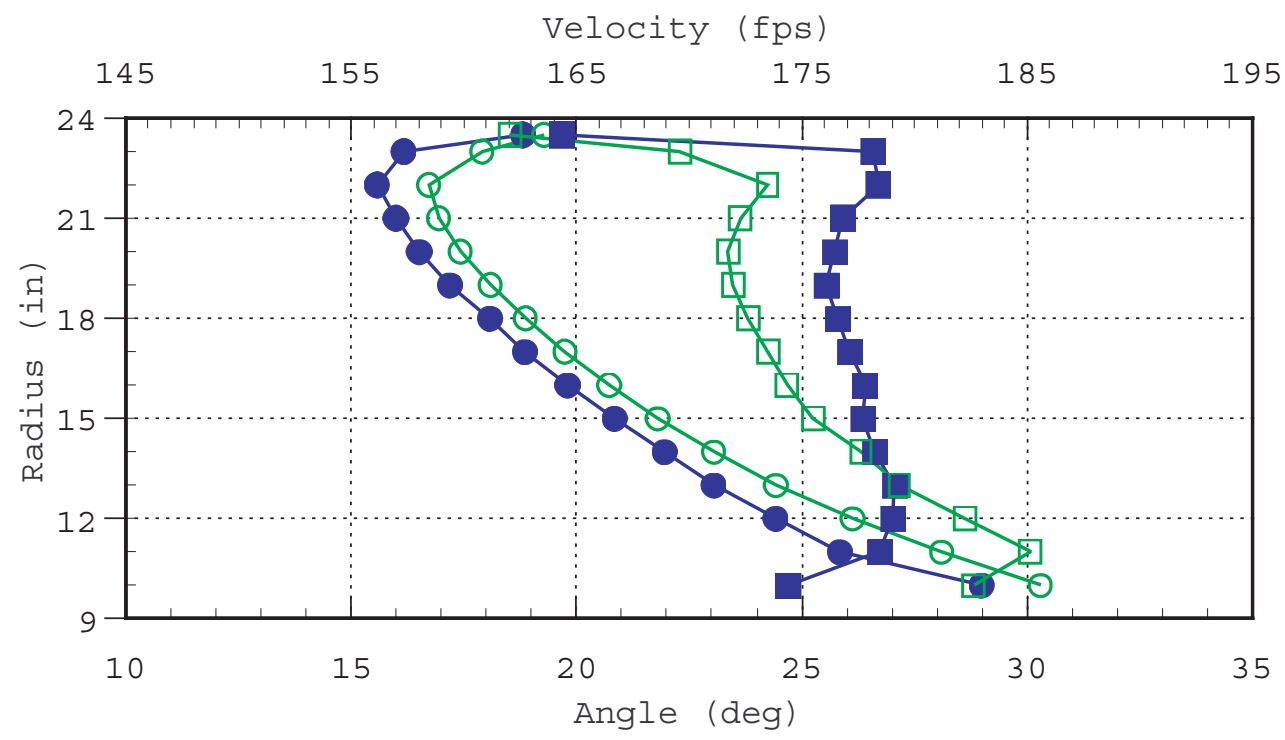

(a) Trailing Edge Inserts

\begin{tabular}{|l|}
\hline- velocity (experimental) \\
$\square-$ velocity (CFD) \\
$\square-$ angle (experimental) \\
$\square-$ angle (CFD)
\end{tabular}

NOTE :

Experiment measurement plane was

5.0" from rotor trailing edge.

CFD computational plane was

$2.2 "$ from rotor trailing edge.

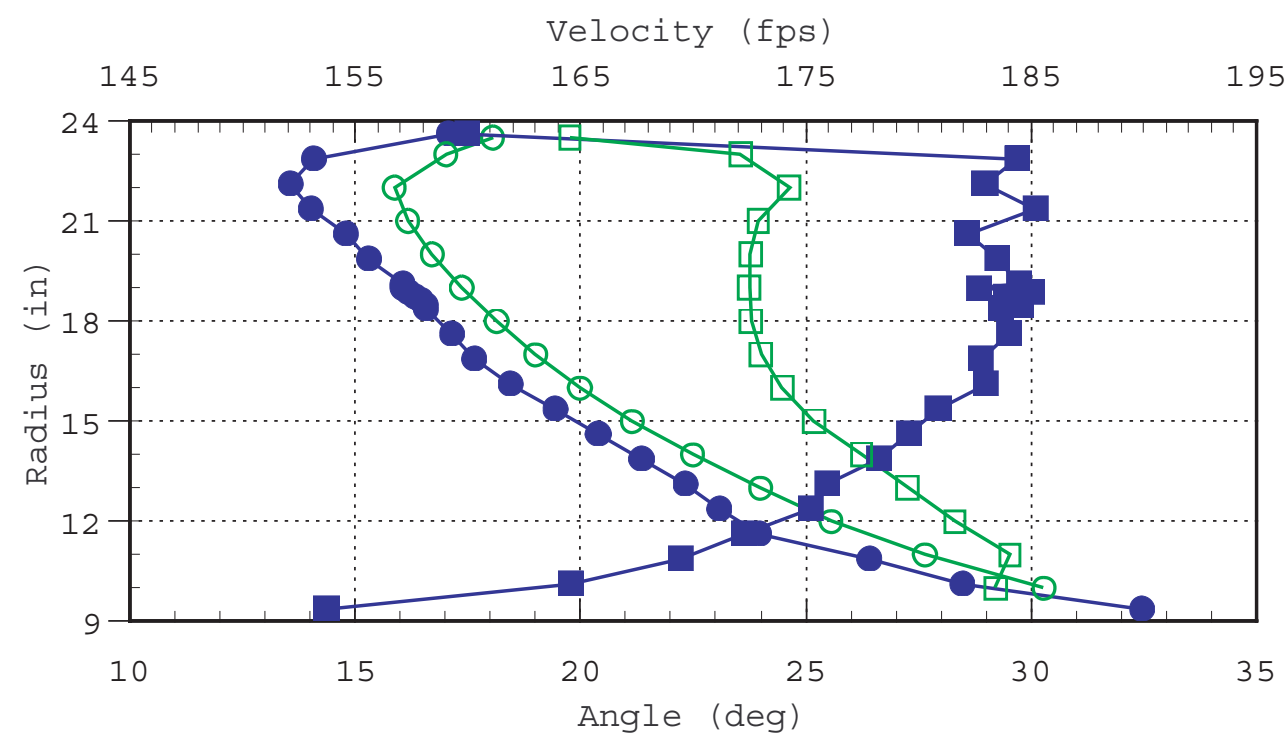

(b) Optimum Blowing

Figure 24. Comparison of predicted and experimental flow parameters downstream of the fan 
Radius

(inches)

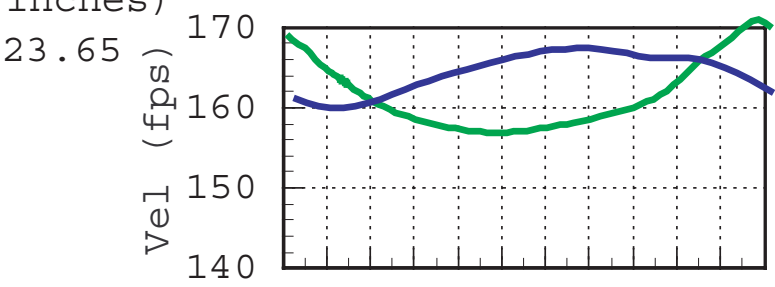

22

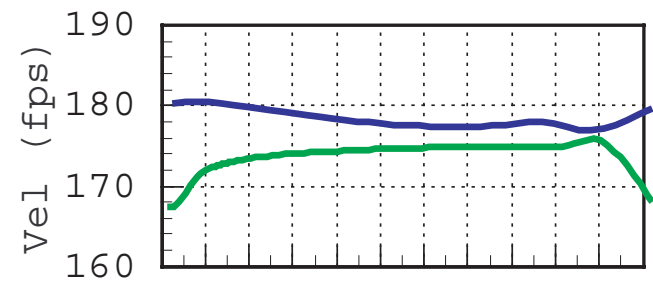

19

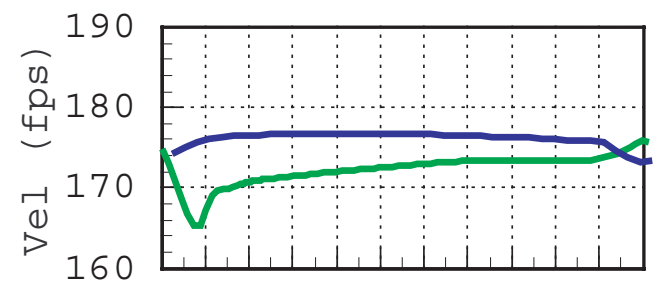

16

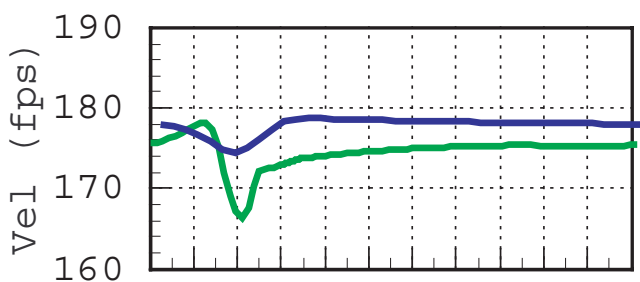

13

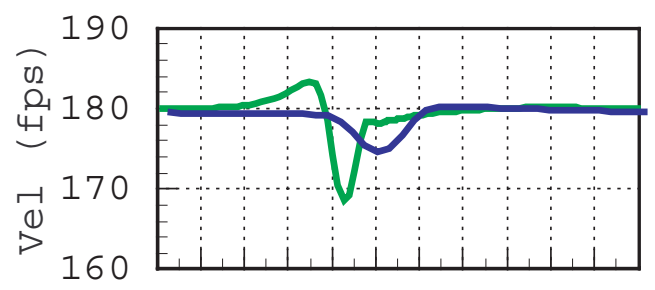

10

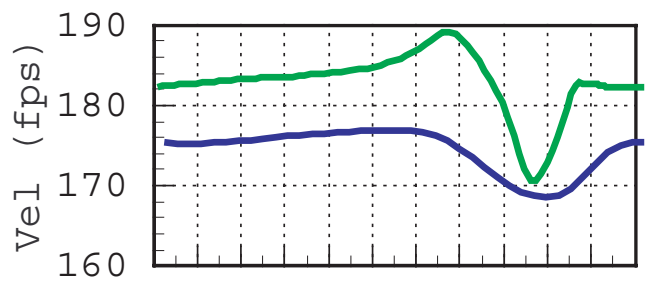

CFD Results

(blunt trailing edge)
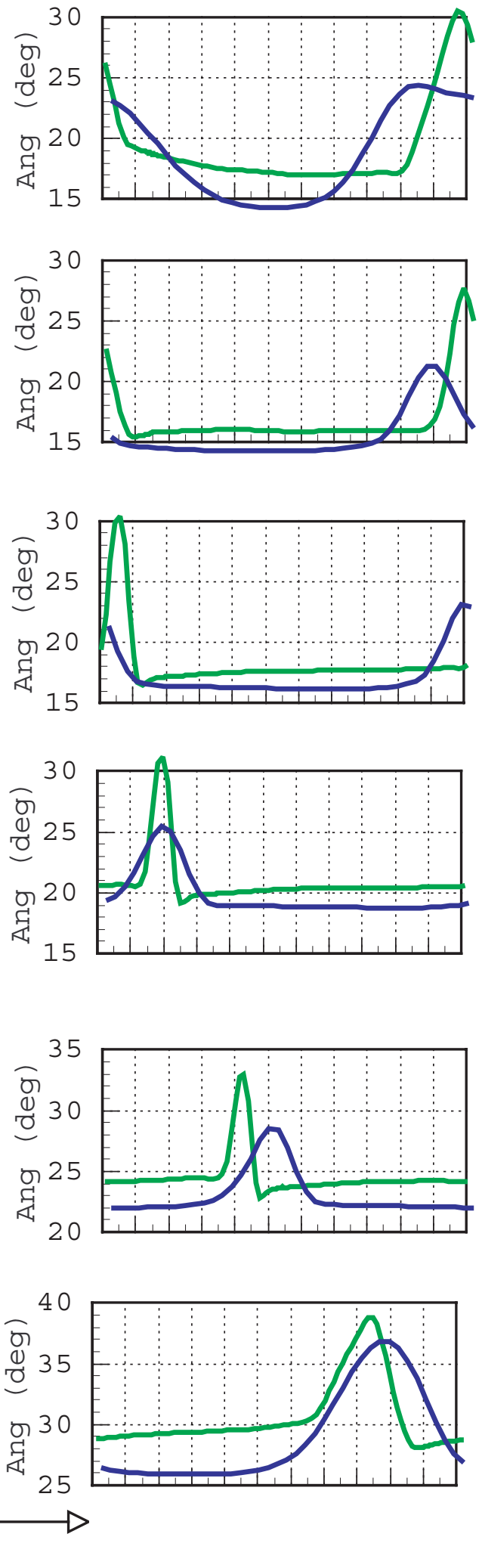

Figure 25. Comparison of measured and predicted fan wake profiles with trailing edge inserts 
Radius
(inches)

23.65

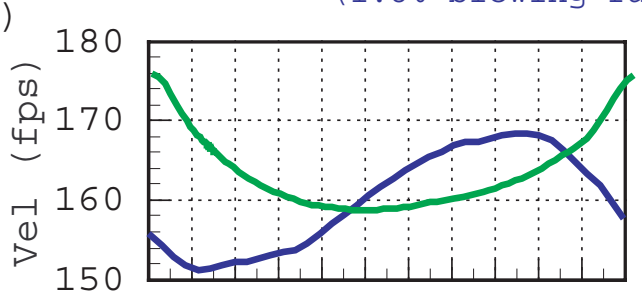

22

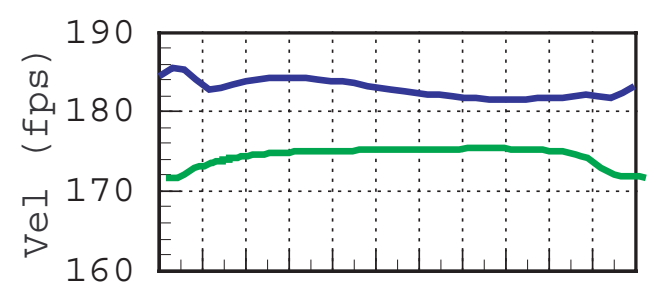

19

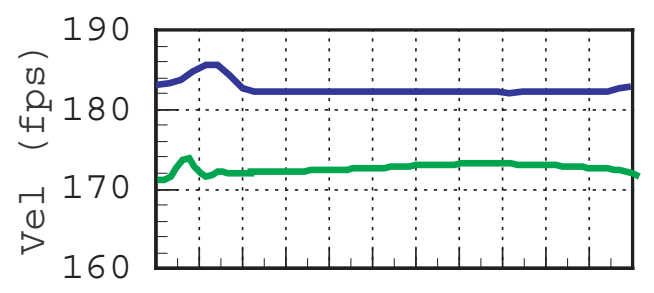

16

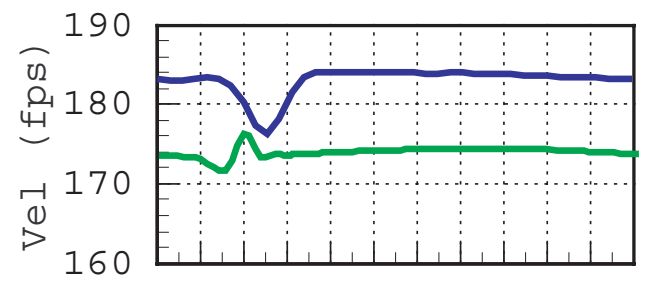

13

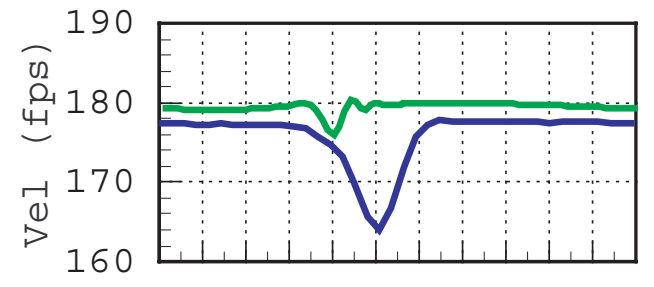

10

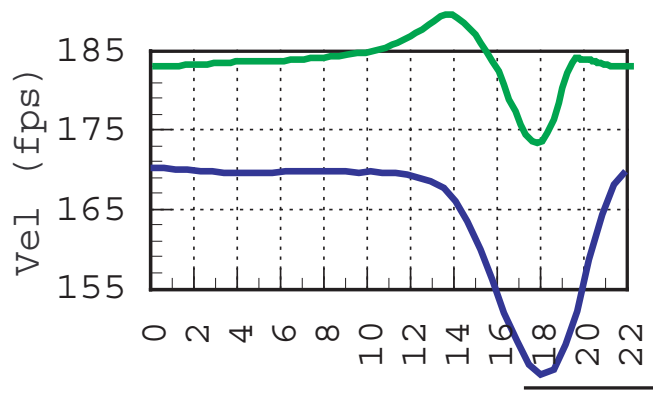

CFD Results

(2.0\% blowing rate)
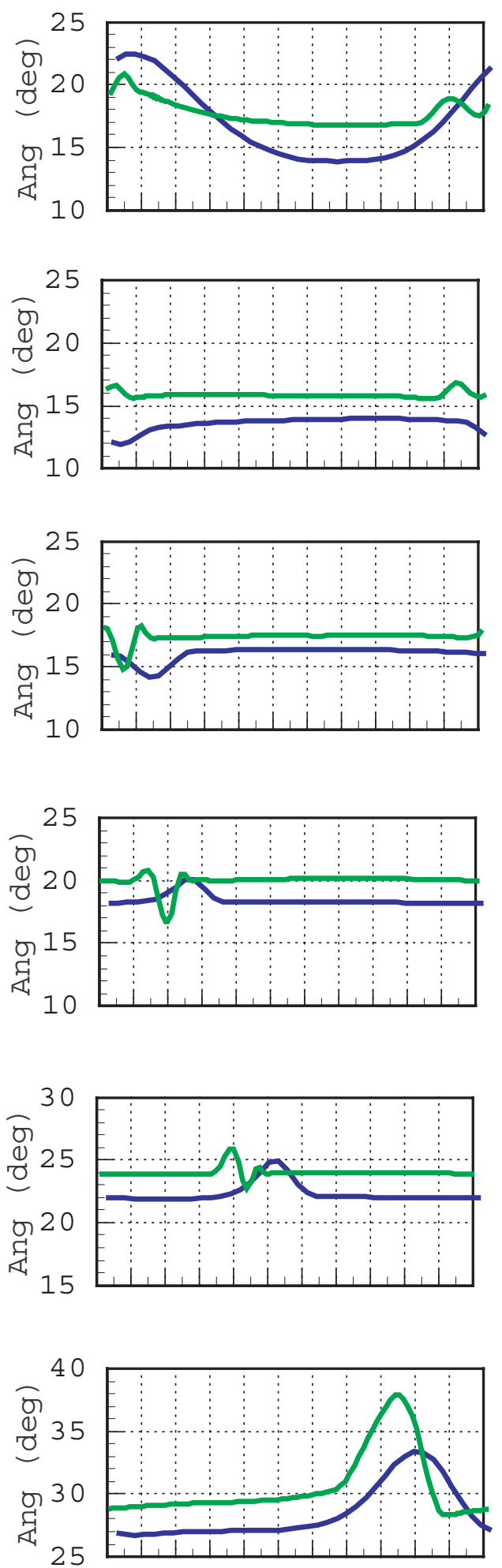

Figure 26. Comparison of measured and predicted fan wake profiles with optimum blowing 

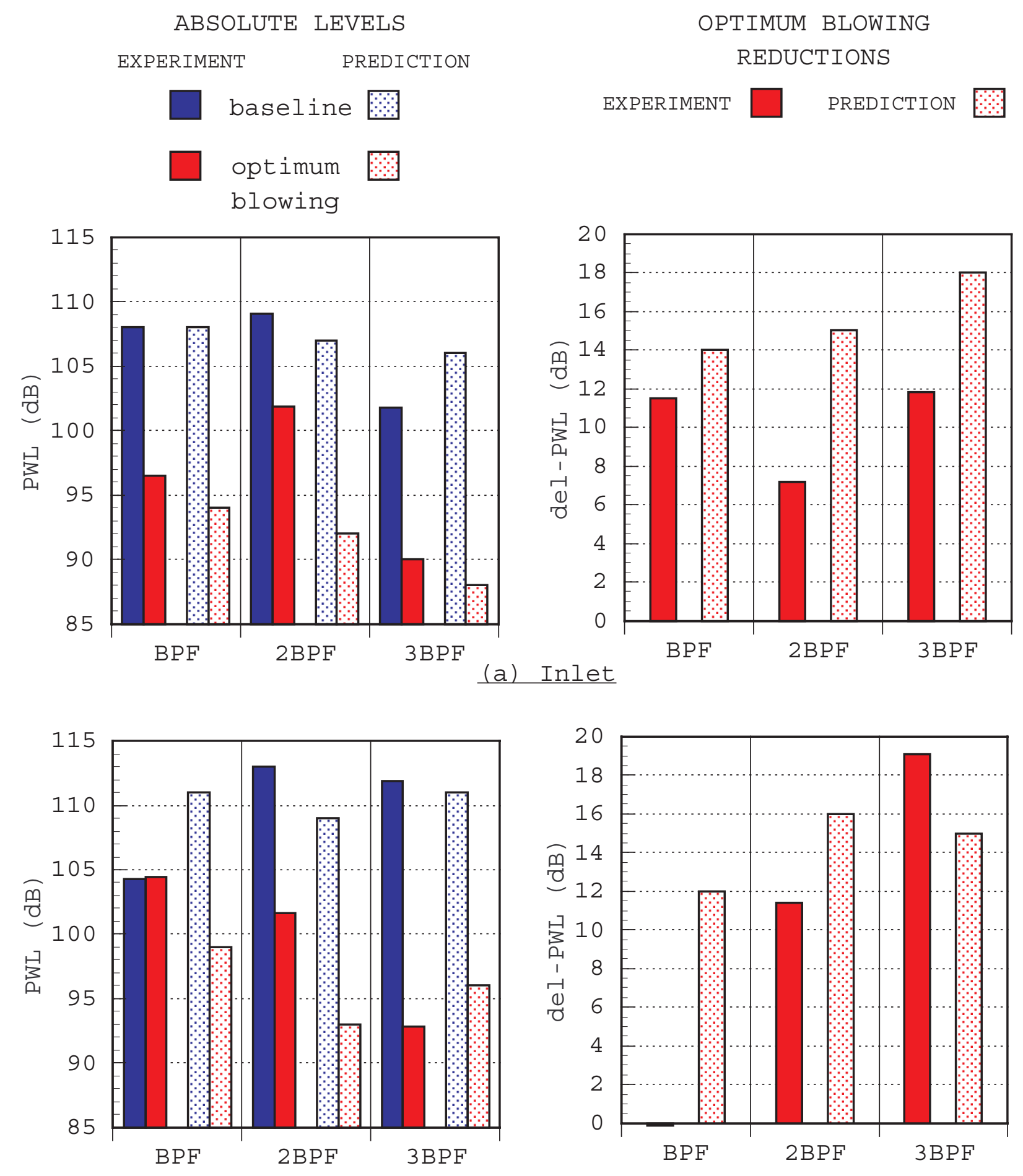

(b) Exhaust

Figure 27. Comparison of measured and predicted tone power levels 
Public reporting burden for this collection of information is estimated to average 1 hour per response, including the time for reviewing instructions, searching existing data sources, gathering and maintaining the data needed, and completing and reviewing the collection of information. Send comments regarding this burden estimate or any other aspect of this collection of information, including suggestions for reducing this burden, to Washington Headquarters Services, Directorate for Information Operations and Reports, 1215 Jefferson Davis Highway, Suite 1204, Arlington, VA 22202-4302, and to the Office of Management and Budget, Paperwork Reduction Project (0704-0188), Washington, DC 20503.

\begin{tabular}{|l|c|c|}
\hline 1. AGENCY USE ONLY (Leave blank) & $\begin{array}{c}\text { 2. REPORT DATE } \\
\text { May } 2002\end{array}$ & $\begin{array}{r}\text { 3. REPORT TYPE AND DATES COVERED } \\
\text { Technical Memorandum }\end{array}$
\end{tabular}

\section{TITLE AND SUBTITLE} 5. FUNDING NUMBERS

Low-Speed Fan Noise Reduction With Trailing Edge Blowing

6. AUTHOR(S)

WU-781-30-11-00

Daniel L. Sutliff, Daniel L. Tweedt, E. Brian Fite, and Edmane Envia

7. PERFORMING ORGANIZATION NAME(S) AND ADDRESS(ES)

National Aeronautics and Space Administration

John H. Glenn Research Center at Lewis Field

Cleveland, Ohio 44135-3191

8. PERFORMING ORGANIZATION REPORT NUMBER

E-13339

\section{SPONSORING/MONITORING AGENCY NAME(S) AND ADDRESS(ES)}

10. SPONSORING/MONITORING AGENCY REPORT NUMBER

National Aeronautics and Space Administration

Washington, DC 20546-0001

NASA TM-2002-211559

\section{SUPPLEMENTARY NOTES}

Prepared for the Eighth Aeroacoustics Conference cosponsored by the American Institute of Aeronautics and Astronautics and the Confederation of European Aerospace Societies, Breckenridge, Colorado, June 17-19, 2002. Daniel L. Sutliff, SEST, Inc., Middleburg Heights, Ohio; Daniel L. Tweedt, AP Solutions, Inc., Cleveland, Ohio; and E. Brian Fite and Edmane Envia, NASA Glenn Research Center. Responsible person, Daniel L. Sutliff, organization code 5940, 216-433-6290.

\begin{tabular}{l|l} 
12a. DISTRIBUTION/AVAILABILITY STATEMENT & 12b. DISTRIBUTION CODE
\end{tabular}

Unclassified - Unlimited

Subject Categories: 07 and 71

Distribution: Nonstandard

Available electronically at http://gltrs.grc.nasa.gov/GLTRS

This publication is available from the NASA Center for AeroSpace Information, 301-621-0390.

\section{ABSTRACT (Maximum 200 words)}

An experimental proof-of-concept test was conducted to demonstrate reduction of rotor-stator interaction noise through rotor-trailing edge blowing. The velocity deficit from the viscous wake of the rotor blades was reduced by injecting air into the wake from a trailing edge slot. Composite hollow rotor blades with internal flow passages were designed based on analytical codes modeling the internal flow. The hollow blade with interior guide vanes creates flow channels through which externally supplied air flows from the root of the blade to the trailing edge. The impact of the rotor wake-stator interaction on the acoustics was also predicted analytically. The Active Noise Control Fan, located at the NASA Glenn Research Center, was used as the proof-of-concept test bed. In-duct mode and farfield directivity acoustic data were acquired at blowing rates (defined as mass supplied to trailing edge blowing system divided by fan mass flow) ranging from 0.5 to 2.0 percent. The first three blade passing frequency harmonics at fan rotational speeds of 1700 to $1900 \mathrm{rpm}$ were analyzed. The acoustic tone power levels (PWL) in the inlet and exhaust were reduced 11.5 and $-0.1,7.2$ and 11.4, 11.8 and 19.4 PWL dB, respectively. The farfield tone power levels at the first three harmonics were reduced 5.4, 10.6, and 12.4 dB PWL. At selected conditions, two-component hotwire and stator vane unsteady surface pressures were acquired. These measurements illustrate the physics behind the noise reduction.

\begin{tabular}{|c|c|c|c|}
\hline \multicolumn{3}{|l|}{ 14. SUBJECT TERMS } & $\begin{array}{c}\text { 15. NUMBER OF PAGES } \\
41\end{array}$ \\
\hline
\end{tabular}

